\title{
Pharmacologic Characterization of JNJ-42226314, [1-(4-Fluorophenyl)indol-5-yl]-[3-[4-(thiazole-2-carbonyl) piperazin-1-yl]azetidin-1-yl]methanone, a Reversible, Selective, and Potent Monoacylglycerol Lipase Inhibitor@
}

\author{
(D) Ryan M. Wyatt, lan Fraser, Natalie Welty, Brian Lord, Michelle Wennerholm, \\ Steven Sutton, Michael K. Ameriks, Christine Dugovic, Sujin Yun, Allison White, \\ Leslie Nguyen, Tatiana Koudriakova, Gaochao Tian, Javier Suarez, Lawrence Szewczuk, \\ William Bonnette, Kay Ahn, Brahma Ghosh, Christopher M. Flores, Peter J. Connolly, \\ Bin Zhu, Mark J. Macielag, Michael R. Brandt, Kristen Chevalier, Sui-Po Zhang, \\ Timothy Lovenberg, and Pascal Bonaventure
}

Janssen Research \& Development, LLC, San Diego, California

Received August 16, 2019; accepted December 1, 2019

\begin{abstract}
The serine hydrolase monoacylglycerol lipase (MAGL) is the ratelimiting enzyme responsible for the degradation of the endocannabinoid 2-arachidonoylglycerol (2-AG) into arachidonic acid and glycerol. Inhibition of 2-AG degradation leads to elevation of 2-AG, the most abundant endogenous agonist of the cannabinoid receptors (CBs) CB1 and CB2. Activation of these receptors has demonstrated beneficial effects on mood, appetite, pain, and inflammation. Therefore, MAGL inhibitors have the potential to produce therapeutic effects in a vast array of complex human diseases. The present report describes the pharmacologic characterization of [1-(4-fluorophenyl)indol-5-yl]-[3-[4-(thiazole-2carbonyl)piperazin-1-yl]azetidin-1-yl]methanone (JNJ-42226314), a reversible and highly selective MAGL inhibitor. JNJ-42226314 inhibits MAGL in a competitive mode with respect to the 2-AG substrate. In rodent brain, the compound time- and dosedependently bound to MAGL, indirectly led to CB1 occupancy by raising 2-AG levels, and raised norepinephrine levels in cortex. In vivo, the compound exhibited antinociceptive efficacy in both the rat complete Freund's adjuvant-induced radiant heat hypersensitivity and chronic constriction injury-induced cold hypersensitivity models of inflammatory and neuropathic pain,
\end{abstract}

\section{Introduction}

The endocannabinoid system is comprised of the G-protein-coupled receptors cannabinoid receptor (CB) type 1 and $\mathrm{CB}$ type 2 and their endogenous ligands

Parts of the manuscript has been presented in poster form: "Dose-dependent effects of the competitive, reversible MGL inhibitor JNJ-42226314 on in vivo measures of neural activity in rats" Society for Neuroscience Annual Meeting; 231.01; San Diego, CA, 2018.

Chemical structure statement: The chemical structure of the JNJ-42226314 discussed here is presented in Fig. 1 in accordance with the journal's editorial policy.

All authors were employees of Janssen Research and Development at the time the research was conducted.

https://doi.org/10.1124/jpet.119.262139.

S This article has supplemental material available at jpet.aspetjournals.org. respectively. Though $30 \mathrm{mg} / \mathrm{kg}$ induced hippocampal synaptic depression, altered sleep onset, and decreased electroencephalogram gamma power, $3 \mathrm{mg} / \mathrm{kg}$ still provided approximately $80 \%$ enzyme occupancy, significantly increased 2-AG and norepinephrine levels, and produced neuropathic antinociception without synaptic depression or decreased gamma power. Thus, it is anticipated that the profile exhibited by this compound will allow for precise modulation of 2-AG levels in vivo, supporting potential therapeutic application in several central nervous system disorders.

\section{SIGNIFICANCE STATEMENT}

Potentiation of endocannabinoid signaling activity via inhibition of the serine hydrolase monoacylglycerol lipase (MAGL) is an appealing strategy in the development of treatments for several disorders, including ones related to mood, pain, and inflammation. [1-(4-Fluorophenyl)indol-5-yl]-[3-[4-(thiazole-2-carbonyl)piperazin-1-yl]azetidin-1-yl]methanone is presented in this report to be a novel, potent, selective, and reversible noncovalent MAGL inhibitor that demonstrates dose-dependent enhancement of the major endocannabinoid 2-arachidonoylglycerol as well as efficacy in models of neuropathic and inflammatory pain. 2-arachidonoylglycerol (2-AG) and $N$-arachidonoylethanolamine as well as the enzymes responsible for the synthesis and degradation of these molecules (Basavarajappa, 2007). Endocannabinoid system activation in the central nervous system (CNS) modulates neural activity, affecting an array of CNS functions such as mood, cognition, pain, and appetite (Zou and Kumar, 2018).

Drugs acting on the endocannabinoid system have been regularly used for their various therapeutic effects. The main psychoactive ingredient of Cannabis sativa, $\Delta 9$-tetrahydrocannabinol (THC), a direct, partial CB1 agonist, has demonstrated beneficial effects on mood. Conversely, the CB1 inverse agonist rimonabant, launched for the treatment of obesity, was later withdrawn because of increased incidences of depression and suicidal ideation (Christensen et al., 2007). THC and 
other exogenous CB1 agonists are also used clinically for treatment of nausea, pain, and epilepsy (Robson, 2014) but induce undesirable CNS side effects that limit their utility as pharmaceuticals (Mulvihill and Nomura, 2013; Tuo et al., 2017). Augmenting endocannabinoids, such as 2-AG, have emerged as an alternative approach to leverage the therapeutic potential of the endocannabinoid system (Patel et al., 2017). Specifically, selective inhibition of the serine hydrolase monoacylglycerol lipase (MAGL), the primary enzyme responsible for 2-AG degradation, presents an appealing yet challenging mechanism by which to achieve this aim. A significant advantage is that only brain regions actively producing $2-\mathrm{AG}$ would be potentiated, likely minimizing potential side effects associated with CNS-wide activation by exogenous CB1 agonists. The challenge resides in achieving MAGL selectivity over the numerous serine hydrolases that share a related catalytic mechanism (Long and Cravatt, 2011).

Patients with major depression and post-traumatic stress disorder have decreased circulating 2-AG levels (Hill et al., 2008, 2009, 2013; Hill and Gorzalka, 2009). Moreover, circulating 2-AG levels were reduced in subjects exposed to chronic stressors, which correlated with reduced measures of positive emotions (Yi et al., 2016). Genetic deletion of MAGL in rodents increases brain 2-AG approximately 10-fold (Schlosburg et al., 2010), whereas pharmacologic MAGL inhibition also elevates brain and peripheral 2-AG and produces several CB1- and/or CB2dependent anxiolytic, antinociceptive, and anti-inflammatory effects (Long et al., 2009a,b; Ghosh et al., 2013; Bernal-Chico et al., 2015; Bedse et al., 2017, 2018; Patel et al., 2017). Additionally, MAGL inhibition may exert therapeutic effects independent of CB1/2-mediated pathways. Arachidonic acid produced from 2-AG hydrolysis by MAGL is a precursor to proinflammatory prostaglandins (Funk, 2001), and inhibiting MAGL reduces neuroinflammatory signaling in animal models of brain injury, neurodegeneration, and status epilepticus (Nomura et al., 2011; Chen et al., 2012; Katz et al., 2015; von Rüden et al., 2015). Thus, MAGL inhibition presents an intriguing therapeutic approach for the treatment of many complex diseases. Notably, MAGL inhibition does not elicit the range of behavioral impairments seen with THC and other CB1 agonists (Mulvihill and Nomura, 2013; Tuo et al., 2017).

Most selective MAGL inhibitors described to date exert their effects via irreversible, covalent binding to the target enzyme (Long et al., 2009a; Griebel et al., 2015; Cisar et al., 2018; Clapper et al., 2018; McAllister et al., 2018). This presents potential therapeutic advantages in that long-lasting target engagement may be achieved at relatively low doses, with restoration of activity being dependent upon new enzyme synthesis. There are, however, certain potentially important pharmaceutic risks associated with covalent inhibitors, namely idiosyncratic immune-mediated drug toxicity (Johnson et al., 2010) as well as reported CB desensitization and tolerance development (Schlosburg et al., 2010). As such, several groups have recently reported on the discovery of noncovalent, reversible MAGL inhibitors (Schalk-Hihi et al., 2011; HernándezTorres et al., 2014; Aghazadeh Tabrizi et al., 2018; Aida et al., 2018; Granchi et al., 2019) as a means of reducing the likelihood of such unwanted effects.

This report describes the pharmacologic characterization of the reversible, competitive MAGL inhibitor, [1-(4-fluorophenyl) indol-5-yl]-[3-[4-(thiazole-2-carbonyl)piperazin-1-yl]azetidin-1yl]methanone (JNJ-42226314). This potent compound was highly selective for MAGL relative to other serine hydrolases. Systemic administration in rats and mice led to time- and dosedependent MAGL engagement as well as elevated brain 2-AG concentrations. The compound was then tested in rats, wherein dose-dependent effects were observed in vivo in established functional readouts known to be influenced by endocannabinoid signaling, including synaptic transmission, electroencephalogram (EEG) gamma power, and inflammatory and neuropathic nociceptive hypersensitivity. An overall dose-dependent increase in wakefulness was also observed, which was associated with increased cortical levels of the wake-promoting neurotransmitter norepinephrine.

\section{Materials and Methods}

Drugs and Reagents. JNJ-42226314 was synthesized at Janssen Research \& Development, LLC (Fig. 1). Synthesis is described in U.S. patent 8,362,000. The tool compound SAR-127303 (1,1,1,3,3,3-hexafluoropropan-2-yl 4-(((4-chlorophenyl)sulfonamido)methyl)piperidine-1-carboxylate) was also synthesized at Janssen Research \& Development, LLC according to procedures described in the literature (Griebel et al., 2015). 1,1,1,3,3,3-Hexafluoropropan-2-yl 4-((4-chlorophenyl)sulfonamido-2-tritio)methyl)piperidine-1-carboxylate $\left(\left[{ }^{3} \mathrm{H}\right]\right.$ SAR-127303) (see Supplemental Material) and 1,3-dihydroxypropan-2-yl-1-tritio oleate $\left(\left[{ }^{3} \mathrm{H}\right] 2-\mathrm{OG}\right)$ were prepared at Moravek, Inc. (Brea, CA). $\left[{ }^{3} \mathrm{H}\right] 2-[(1 \mathrm{R}, 2 \mathrm{R}, 5 \mathrm{R})-$ 5-hydroxy-2-(3-hydroxypropyl)cyclohexyl]-5-(2-methyloctan-2-yl)phenol (CP-55940) was purchased from Perkin-Elmer (Waltham, MA). $N$ methyl- $N$-[[3-(4-pyridinyl)phenyl]methyl]-carbamic acid 4'-(aminocarbonyl)[1,1'-biphenyl]-4-yl ester (WWL-70), 4-nitrophenyl-4-[bis(1,3-benzodioxol-5-yl)(hydroxy)methyl]piperidine-1-carboxylate (JZL-184), 4-[bis(1,3-benzodioxol-5-yl)hydroxymethyl]-1-piperidinecarboxylic acid 2,2,2-trifluoro-1-(trifluoromethyl)ethyl ester (KML-29), and 1(2,4-dichlorophenyl)-5-(4-iodophenyl)-4-methyl- $N$-(1-piperidyl)pyrazole-3-carboxamide (AM-251) were obtained from Tocris (Minneapolis, MN). N-3-pyridinyl-4-[[3-[[5-(trifluoromethyl)-2-pyridinyl] oxy]phenyl]methyl]-1-piperidinecarboxamide (PF-3845) was purchased from Sigma-Aldrich (St. Louis, MO). Methyl arachidonyl fluorophosphonate (MAFP) was obtained from Cayman Chemical

\footnotetext{
ABBREVIATIONS: 2-AG, 2-arachidonoylglycerol; ABPP, activity-based protein profiling; AP, anterior-posterior; AUC, area under the curve; BSA, bovine serum albumin; CB, cannabinoid receptor; CCI, chronic constriction injury; CFA, complete Freund's adjuvant; CP-55940, 2-[(1R,2R,5R)-5hydroxy-2-(3-hydroxypropyl)cyclohexyl]-5-(2-methyloctan-2-yl)phenol; CPM, counts per minute; DSI, Data Sciences International; ED ${ }_{50}$, $50 \%$ effective dose; EEG, electroencephalogram; FAAH, fatty acid amide hydrolase; fEPSP, field excitatory postsynaptic potential; FP-Rh, fluorophosphonate carboxytetramethylrhodamine; $\left[{ }^{3} \mathrm{H}\right]$ 2-OG, 1,3-dihydroxypropan-2-yl-1-tritio oleate; $\left[{ }^{3} \mathrm{H}\right]$ SAR-127303, 1,1,1,3,3,3-hexafluoropropan-2-yl 4-(((4-chlorophenyl)sulfonamido-2-tritio)methyl)piperidine-1-carboxylate; HP- $\beta$-CD, (2-hydroxyproplyl)- $\beta$-cyclodextrin; JNJ-42226314, [1-(4-fluorophenyl)indol-5-yl]-[3-[4-(thiazole-2-carbonyl)piperazin-1-yl]azetidin-1-yl]methanone; JZL-184, 4-nitrophenyl-4-[bis(1,3-benzodioxol-5yl)(hydroxy)methyl]piperidine-1-carboxylate; KML-29, 4-[bis(1,3-benzodioxol-5-yl)hydroxymethyl]-1-piperidinecarboxylic acid 2,2,2-trifluoro-1(trifluoromethyl)ethyl ester; LC, liquid chromatography; MAGL, monoacylglycerol lipase; MS, mass spectrometry; MS/MS, tandem MS; NE, norepinephrine; NREM, non-REM; PBMC, peripheral blood mononuclear cell; PF-3845, N-3-pyridinyl-4-[[3-[[5-(trifluoromethyl)-2-pyridinyl]oxy]phenyl] methyl]-1-piperidinecarboxamide; REM, rapid eye movement; SAR-127303, 1,1,1,3,3,3-hexafluoropropan-2-yl 4-(((4-chlorophenyl)sulfonamido) methyl)piperidine-1-carboxylate; THC, tetrahydrocannabinol.
} 
(Ann Arbor, MI). The fluorophosphonate carboxytetramethylrhodamine (FP-Rh) (Liu et al., 1999) probe was synthesized according to previously reported procedures (Kidd et al., 2001; Patricelli et al., 2001) and modifications thereof. The synthesized material was purified by preparative high-performance liquid chromatography (HPLC) (Column: Xtimate C18 150*25 mm*5 $\mu \mathrm{m}$ ) under mildly basic conditions (A: $10 \mathrm{mM}$ ammonium bicarbonate, B: acetonitrile). After lyophilization, pure FP-Rh was obtained as a purple solid that was stored under inert conditions at $-20^{\circ} \mathrm{C}$ until further use or at $-80^{\circ} \mathrm{C}$ as argon-purged DMSO aliquots. Structure and analytical purity were confirmed by NMR $\left({ }^{1} \mathrm{H},{ }^{31} \mathrm{P},{ }^{19} \mathrm{~F}\right)$ and electrospray ionization mass spectrometry (ESI-MS) techniques.

Compounds were dissolved in DMSO for in vitro studies. For in vivo studies, drugs were freshly prepared daily in $20 \%$ (2-hydroxyproplyl)$\beta$-cyclodextrin (HP- $\beta$-CD) for intraperitoneal administration.

In Vitro MAGL Activity Assay. The assay used to measure the in vitro activity of MAGL was adapted from the substrate cleavage assay used for another serine hydrolase, fatty acid amide hydrolase (FAAH), described in Wilson et al. (2003). The assay consists of combining MAGL from HeLa cells, rat/mouse brain membranes, or human peripheral blood mononuclear cells with test compounds (JNJ-42226314, JZL-184, KML-29, and SAR-127303); adding $\left[{ }^{3} \mathrm{H}\right]$ 2 -OG; and measuring the amount of cleaved $\left[1,3-{ }^{3} \mathrm{H}\right]$-glycerol that passes through an activated carbon filter. The amount of cleaved $\left[{ }^{3} \mathrm{H}\right]$-glycerol passing through the carbon filter is proportional to the activity of the MAGL enzyme. The substrate $\left[{ }^{3} \mathrm{H}\right]$ 2-OG (Moravek) was found to be more stable than $\left[{ }^{3} \mathrm{H}\right] 2-\mathrm{AG}$ (Moravek) and, therefore, was used for this assay.

HeLa cells (ATCC, Manassa, VA) were grown to confluence in 15-cm tissue culture dishes in complete medium (Eagle's minimum essential medium; Lonza, Basel, Switzerland) containing 10\% fetal bovine serum, nonessential amino acids, sodium pyruvate, glutamine, and $100 \mathrm{IU} / \mathrm{ml}$ penicillin/streptomycin. Once the cells reached confluence, the medium was aspirated, and cells were removed with Dulbecco's phosphate-buffered saline and $5 \mathrm{mM}$ EDTA. The cells were counted and then centrifuged for 5 minutes at $300 \mathrm{~g}$, and the supernatant was removed. The HeLa cell pellet was homogenized using a Polytron in assay buffer containing $125 \mathrm{mM}$ Tris, $1 \mathrm{mM}$ EDTA, $0.02 \%$ Triton-X100, and 0.4 mM HEPES $(\mathrm{pH}=7.4)$ in a volume yielding 500,000 cells $/ \mathrm{ml}$. The enzyme reaction combined test compound ( $0.1 \mathrm{nM}$ to $10 \mu \mathrm{M})$, HeLa cell homogenate (diluted to a final concentration of 2000 cell equivalents/well final), and $300 \mathrm{nM}$ $\left[{ }^{3} \mathrm{H}\right] 2$-OG $(70,000$ counts per minute $(\mathrm{CPM}) /$ well, specific activity $10-20 \mathrm{Ci} / \mathrm{mmol}$ ). Compounds (from 0.1 to $10 \mu \mathrm{M}$, diluted from $10 \mathrm{mM}$ DMSO stocks) were incubated with the HeLa cell homogenate for 30 minutes prior to adding the radiolabeled substrate, and then the complete mixture was incubated for 1 hour at room temperature in a total volume of $25 \mu \mathrm{l} /$ well. In preparation for the filtration step, powdered charcoal was suspended in methanol and vortexed to wet the charcoal. Glycerol was added to help maintain the suspension, and the solution was buffered to $\mathrm{pH} 7.0$ with $100 \mathrm{mM}$ Tris. The final suspension was $20 \% \mathrm{v} / \mathrm{v}$ charcoal, $20 \% \mathrm{v} / \mathrm{v}$ methanol, and $20 \% \mathrm{v} / \mathrm{v}$ glycerol in $100 \mathrm{mM}$ Tris. Thirty-five microliters of the charcoal mix was added per well, and the liquid was vacuumed through the filter plate prior to adding the reaction sample. After enzyme incubation for 1 hour at room temperature, $20 \mu \mathrm{l}$ of the reaction was transferred to the charcoal plate and incubated for 5 minutes. The filter plate was then placed on top of a recipient plate containing $65 \mu \mathrm{l}$ Microscint-PS. The reaction was centrifuged to flow the reaction through the charcoal and into the Microscint-PS. The plate containing the Microscint-PS and reaction product was then counted on a Top Count the next day. Percentage inhibition of enzyme activity was calculated using the following formula: $\%$ inhibition $=100-((\mathrm{CPM}$ observed - low control CPM)/(high control CPM - low control CPM) $\times$ 100), where low control CPM $=$ substrate + HeLa cell homogenate + $10 \mu \mathrm{M}$ MAGL inhibitor and high control $\mathrm{CPM}=$ substrate $+\mathrm{HeLa}$ cell homogenate. $\mathrm{IC}_{50}$ values were calculated using a one-site model with GraphPad Prism 7.0 (San Diego, CA).

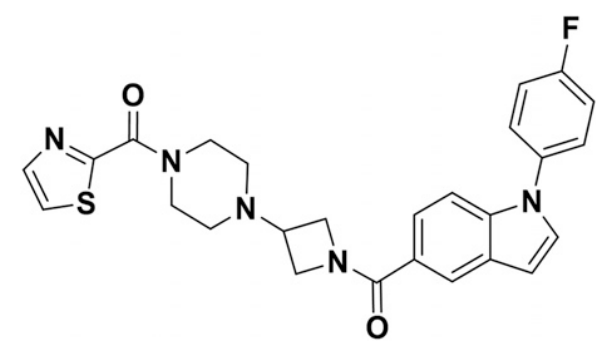

Fig. 1. Chemical structure of JNJ-42226314, [1-(4-fluorophenyl)indol-5yl]-[3-[4-(thiazole-2-carbonyl)piperazin-1-yl]azetidin-1-yl]methanone.

Testing of compound potency was also performed in human peripheral blood mononuclear cells (PBMCs). To harvest PBMCs, $1 \mathrm{ml}$ of fresh whole human blood was aliquoted into a 14-ml Falcon tube (Becton Dickinson, Franklin Lakes, NJ) with $4 \mathrm{ml}$ of room temperature Red Blood Cell Lysing Buffer (Sigma). Tubes were set to incubate at room temperature for 30 minutes using a rocking platform to gently invert the sample. After complete lysis of the sample, tubes were centrifuged at $1800 \mathrm{~g}$ for 10 minutes at room temperature. The supernatant containing lysed red blood cell membranes was carefully removed from the white blood cell pellet, which was resuspended in $1 \mathrm{ml}$ Red Blood Cell Lysing Buffer and centrifuged at $1800 \mathrm{~g}$ for 10 minutes at room temperature. The supernatant was removed, and the pelleted PBMCs were frozen at $-80^{\circ} \mathrm{C}$ until use. For the activity assay, the thawed pellet was resuspended in $50 \mathrm{ml}$ assay buffer and used in the enzyme reaction as previously described.

Testing of compound potency was also performed in mouse and rat soluble brain fractions. Fresh-frozen mouse or rat brain was homogenized by Polytron in $10 \mathrm{ml} / \mathrm{g}$ Triton-free $125 \mathrm{mM}$ Tris, $1 \mathrm{mM}$ EDTA, and $0.4 \mathrm{mM}$ HEPES $(\mathrm{pH}=7.4)$ on ice. The homogenate was centrifuged at $1000 \mathrm{~g}$ for 10 minutes at $4^{\circ} \mathrm{C}$. The supernatant fraction was then centrifuged at $35,000 \mathrm{~g}$ for 30 minutes at $4^{\circ} \mathrm{C}$. The supernatant fraction from the high-speed centrifugation was kept on ice and used as the enzyme source for the reaction. The supernatant fraction was diluted $\sim 200 \times$ in assay buffer to yield an approximate final protein concentration of $17 \mu \mathrm{g} / \mathrm{ml}$ and used in the enzyme reaction as previously described.

Expression and Purification of Recombinant Human MAGL. Recombinant human MAGL was prepared according to a procedure published previously (Labar et al., 2007). Briefly, N-terminal 6His-tagged and C-terminal strep-tagged human MAGL was overexpressed in Escherichia coli BL21(DE3) cells. After cell pellet lysis, MAGL was purified from crude extract by nickel, size exclusion, and ion exchange (Hi trap Q) chromatography. Protein purity was evaluated by SDS-PAGE electrophoresis. Pure fractions were pooled, concentrated, and stored at $-80^{\circ} \mathrm{C}$ in $50 \mathrm{mM}$ sodium carbonate containing $208 \mathrm{mM} \mathrm{NaCl}$ and $1 \mathrm{mM}$ Tris(2-carboxyethyl)phosphine ( $\mathrm{pH}=9.5$ ).

Inhibition Kinetics. The kinetic mechanism of inhibition of human recombinant MAGL by JNJ-42226314 was determined via an enzymatic assay quantifying arachidonic acid by RapidFire-MS. Briefly, responses of JNJ-42226314 were tested at various substrate (2-AG) concentrations, with initial rates $(v)$ analyzed as a function of substrate (S) and inhibitor (I) concentrations through a global fit via least-squares method to determine the inhibition mechanism according to eq. 1 below (Copeland, 2005). $V_{\max }$ in these equations refers to the maximum velocity, $K_{\mathrm{m}}$ the Michalis-Menten constant, $K_{\mathrm{i}}$ the inhibition constant for the formation of the binary enzyme inhibitor complex, and $\alpha$ the substrate and inhibitor interaction constant for the formation of the tertiary enzyme-substrate inhibitor complex. All enzymatic reactions were run in $50 \mathrm{mM}$ Tris-HCl containing $50 \mathrm{mM} \mathrm{NaCl}, 5 \mathrm{mM} \mathrm{MgCl}{ }_{2}, 1 \mathrm{mM}$ EDTA, $0.002 \%$ Tween20, $0.01 \mathrm{mg} / \mathrm{ml}$ bovine serum albumin (BSA), 7.5\% DMSO, and $2.5 \%$ ethanol $(\mathrm{pH}=7.5)$ in a total volume of $40.4 \mu$ l. Inhibitor 
$(0.4 \mu \mathrm{l})$, which was serially diluted in pure DMSO, was added to a 384well plate (Greiner, Monroe, NC). Substrate (2-AG) (20 $\mu \mathrm{l})$, which was serially diluted in assay buffer, was added to the plate containing the test inhibitor. Human recombinant MAGL ( $20 \mu \mathrm{l}$, final concentration $=1 \mathrm{nM}$ ) was added to the substrate-inhibitor mixtures to initiate the reaction. The reaction mixtures were incubated at room temperature $\left(22^{\circ} \mathrm{C}\right)$ for 10 minutes, and the reactions were quenched by adding $10 \mu \mathrm{l}$ formic acid to a final concentration of $1 \%$. The amount of arachidonic acid produced was quantified by RapidFire-MS in a mobile phase of $0.1 \%$ acetic acid in water (solution A) and $90 \%$ acetonitrile in $0.1 \%$ acetic acid (solution $\mathrm{B}$ ).

$$
v=\frac{V_{\max }[\mathrm{S}]}{K_{\mathrm{m}}\left(1+\frac{[\mathrm{I}]}{K_{\mathrm{i}}}\right)+[\mathrm{S}]\left(1+\frac{[\mathrm{I}]}{\alpha K_{\mathrm{i}}}\right)}
$$

In Vitro Equilibrium Binding Assay Using $\left[{ }^{3} \mathbf{H}\right]$ SAR-127303. Compound binding to MAGL was evaluated in plasma membrane preparations from rat, mouse, and human brain samples using $\left[{ }^{3} \mathrm{H}\right]$ SAR-127303 (Moravek). Whole rodent brains were collected immediately after sacrifice by $\mathrm{CO}_{2}$ inhalation and frozen on dry ice. The human brain sample, a fragment of frontal cortex, was obtained from the Anatomy Gifts Registry (Hanover, MD). The subject was an 84-year-old male who perished of causes not directly attributable to CNS disease. Brain samples from all species were homogenized using a PowerGen 35 homogenizer (Fisher Scientific, Hampton, $\mathrm{NH}$ ) in $10 \mathrm{ml} / \mathrm{g} 125 \mathrm{mM}$ Tris, $1 \mathrm{mM}$ EDTA, and $0.4 \mathrm{mM}$ HEPES ( $\mathrm{pH}$ $=7.5$ ) on wet ice. Membrane fractions were prepared by centrifugation. First, debris was removed by low-speed centrifugation ( $1000 \mathrm{~g}$ for 10 minutes at $4^{\circ} \mathrm{C}$ ). The supernatant fraction from the first centrifugation was then centrifuged at $35,000 \mathrm{~g}$ for 30 minutes at $4^{\circ} \mathrm{C}$. The supernatant fraction from the second centrifugation was discarded, and the membrane pellet was reconstituted in $125 \mathrm{mM}$ Tris, $1 \mathrm{mM}$ EDTA, and $0.4 \mathrm{mM}$ HEPES ( $\mathrm{pH}=7.5$ ). Total membrane protein was estimated using a Nanovue (GE Healthcare Life Sciences, Pittsburgh, PA). Membrane samples reconstituted from the membrane pellet were stored at $-80^{\circ} \mathrm{C}$ and used after one thaw.

For equilibrium binding assays, membrane homogenate $(350 \mu \mathrm{g}$ total membrane protein per reaction) was combined with radioligand at various concentrations of the unlabeled compound of interest in a total volume of $100 \mu \mathrm{l}$. The radioligand was $\left[{ }^{3} \mathrm{H}\right] \mathrm{SAR}-127303$ (Moravek) prepared at a specific activity of $10 \mathrm{Ci} / \mathrm{mmol}$ and used at a final concentration of $8 \mathrm{nM}$. Compounds were diluted from $10 \mathrm{mM}$ DMSO stocks. All components were diluted in assay buffer containing $10 \mathrm{mM}$ Tris, $1 \mathrm{mM}$ EDTA, and $1 \%$ bovine serum albumin $(\mathrm{pH}=7.0)$. Reactions were incubated at $21^{\circ} \mathrm{C}$ for 90 minutes in $1.5-\mathrm{ml}$ microfuge tubes (E\&K Scientific, Santa Clara, CA). Reactions were terminated by adding $1 \mathrm{ml}$ of iced binding buffer followed by immediate centrifugation at $20,800 \mathrm{~g}$ for 10 minutes at $4^{\circ} \mathrm{C}$. The supernatant was aspirated, and the pellet was washed twice with $1 \mathrm{ml}$ of iced binding buffer. After aspirating the supernatant of the final wash, the pellet was dissolved in $100 \mu \mathrm{l}$ of $0.5 \mathrm{M} \mathrm{NaOH}$ and then counted in a scintillation counter (LS6500; Beckman Coulter, Fullerton, CA). Results were evaluated using a one-site model (GraphPad Prism 7.0). $\mathrm{IC}_{50}$ values were converted to $\mathrm{K}_{\mathrm{i}}$ values as previously described (Cheng and Prusoff, 1973).

In Vitro Reversibility Assay. Dissociation rates for compounds were determined using conditions similar to those used for equilibrium binding. Briefly, membrane homogenates were combined with an $80 \%$ inhibitory concentration of compound (determined by equilibrium binding above) and preincubated for 60 minutes at $37^{\circ} \mathrm{C}$ with gentle agitation. The reaction was then diluted 15 -fold with radioligand to a final concentration of $8 \mathrm{nM}$. The reaction was terminated at various time points by centrifugation and washed with $10 \mathrm{mM}$ Tris, $1 \mathrm{mM}$ EDTA, and $1 \% \mathrm{BSA}$ ( $\mathrm{pH}=7.5$ ), and radioactivity in the pellet was determined as described above. Dissociation rates were determined using a one-phase exponential decay model (GraphPad Prism 7.0).
In Vitro Competitive Activity-Based Protein Profiling Stud-

ies. Human, rat, and mouse tissues were processed to isolate membrane and soluble fractions as described previously (Nomanbhoy et al., 2003). Briefly, brain or liver samples (Analytical Biologic Services) were Dounce-homogenized in $50 \mathrm{mM}$ HEPES ( $\mathrm{pH}=7.4$ ) containing $320 \mathrm{mM}$ sucrose followed by centrifugation at $1400 \mathrm{~g}$ for 3 minutes to remove the cellular debris. The supernatant was subjected to ultracentrifugation at $145,000 \mathrm{~g}$ for 45 minutes to produce the soluble fraction in the supernatant and the pelleted membrane fraction. The membrane fraction was washed in lysis buffer by Dounce-homogenization, reisolated by ultracentrifugation, and resuspended in lysis buffer by Dounce-homogenization. Total protein concentration was assessed for the soluble and membrane fractions using the bicinchoninic acid assay (ThermoFisher Scientific, Waltham, MA). Samples were diluted to $1 \mathrm{mg} / \mathrm{ml}$ in lysis buffer, snap frozen on liquid nitrogen, and stored at $-80^{\circ} \mathrm{C}$ until use.

Competitive activity-based protein profiling (ABPP) was used as previously described to examine inhibitor selectivity against the serine hydrolase family (Jessani et al., 2002). Briefly, soluble or membrane proteomes $(1 \mathrm{mg} / \mathrm{ml})$ were incubated with inhibitors $(0,1$, or $10 \mu \mathrm{M}$ ) for 30 minutes at room temperature under rotation in a final volume of $50 \mu \mathrm{l}$ lysis buffer containing $10 \mathrm{mM} \mathrm{MgCl} 2$ and DMSO at a final concentration of $2 \%$. FP-Rh probe was then added to the sample at a final concentration of $10 \mu \mathrm{M}$ and further incubated for 30 minutes at room temperature while rotating. Reactions were quenched by adding $25 \mu \mathrm{l}$ of $3 \times$ SDS-PAGE loading buffer and heating to $75^{\circ} \mathrm{C}$ for 10 minutes. Proteins were resolved on a $4 \%-12 \%$ Bolt Bis-Tris minigel (10 $\mu \mathrm{l}$ sample/lane) at $150 \mathrm{~V}$ for 2 hours using $4^{\circ} \mathrm{C}$ chilled $1 \times 4$ morpholinepropanesulfonic acid buffer and Bolt antioxidant in the front compartment of the gel box (ThermoFisher Scientific). The use of chilled running buffer and antioxidant reagent improved the resolution of serine hydrolases. The Chameleon Duo Pre-stained Protein Ladder was used to mark molecular weights on the gels (LICOR Biosciences, Lincoln, NE). Upon completion, gels were rinsed with deionized water and scanned for fluorescence using a Typhoon 9500 system, excitation with 532-nm laser, and long pass green emission filter (GE Life Sciences, Marlborough, MA).

In Vitro Selectivity Panel. JNJ-42226314 selectivity was further assessed in an extensive panel of binding assays including adenosine $\left(\mathrm{A}_{1}, \mathrm{~A}_{2 \mathrm{~A}}, \mathrm{~A}_{3}\right)$, adrenergic $\left(\alpha_{1}, \alpha_{2}, \alpha_{1}\right)$, angiotensin $\left(\mathrm{AT}_{1}\right)$, dopamine $\left(\mathrm{D}_{1}\right.$, $\left.\mathrm{D}_{2}\right)$, bradykinin $\left(\mathrm{B}_{2}\right)$, cholecystokinin $\left(\mathrm{CCK}_{\mathrm{A}}\right)$, galanin $\left(\mathrm{GAL}_{2}\right)$, melato$\operatorname{nin}\left(\mathrm{ML}_{1}\right)$, muscarinic $\left(\mathrm{M}_{1}, \mathrm{M}_{2}, \mathrm{M}_{3}\right)$, neurotensin $\left(\mathrm{NT}_{1}\right)$, neurokinin $\left(\mathrm{NK}_{2}, \mathrm{NK}_{3}\right)$, opiate $(\mu, \kappa, \delta)$, serotonin $\left(5-\mathrm{HT}_{1 \mathrm{~A}}, 5-\mathrm{HT}_{1 \mathrm{~B}}, 5-\mathrm{HT}_{2 \mathrm{~A}}, 5-\mathrm{HT}_{3}\right.$, $\left.5-\mathrm{HT}_{5 \mathrm{~A}}, 5-\mathrm{HT}_{6}, 5-\mathrm{HT}_{7}\right)$, somatostatin, vasopressin $\left(\mathrm{V}_{1 \mathrm{a}}\right)$, dopamine transporter, norepinephrine transporter, and ion channels (sodium, potassium, calcium, and chloride). The assays were performed by Eurofins (Celles L'Evescault, France).

JNJ-42226314 was also tested against an in-house panel of other receptors, enzymes, and ion channels that could potentially mediate analgesic effects, including human cyclooxygenase 1/cyclooxygenase 2 , human transient receptor potential cation channel subfamily $\mathrm{V}$ member 1 receptor (TRPV1), rat N-Type calcium channel, canine transient receptor potential cation channel subfamily melastatin member 8 (TRPM8), human and rat FAAH, and human CB1 and CB2.

In Vivo Studies. All animal experiments were performed in accordance with the Guide for Care and Use of Laboratory Animals adopted by the National Institutes of Health [National Research Council, 2011] and approved by the Janssen Research \& Development Institutional Animal Care and Use Committee. Animals were housed under controlled conditions with a 12-hour light/dark schedule and a temperature of $22 \pm 2^{\circ} \mathrm{C}$. Food and water were provided ad libitum. Experiments were performed after a 1-week acclimation period unless stated otherwise.

Ex Vivo MAGL and CB1 Occupancy Studies. Experiments were performed in 18 male C57Bl/6 mice weighing 20-30 g (The Jackson Laboratory, Bar Harbor, ME) and 27 male Sprague-Dawley rats weighing 300-400 g (Harlan Laboratories, Livermore, CA). Animals 
received intraperitoneal injections of JNJ-42226314 or vehicle before time and dose dependency were assessed. The animals were euthanized with $\mathrm{CO}_{2}$ at varying time points after drug administration ( $n=3$ per time point or dose). Brains were rapidly removed and frozen on powdered dry ice and stored at $-80^{\circ} \mathrm{C}$ until sectioning. Plasma samples were also collected for bioanalysis of JNJ-42226314 and 2-AG by liquid chromatography-tandem MS (LC-MS/MS). Twenty-micrometer-thick tissue sections at the level of the hippocampus were prepared for autoradiography. MAGL radioligand binding was determined at room temperature with $3 \mathrm{nM}\left[{ }^{3} \mathrm{H}\right] \mathrm{SAR}$ $127303(20.7 \mathrm{Ci} / \mathrm{mmol})$ in $50 \mathrm{mM}$ Tris containing $1 \% \mathrm{BSA}(\mathrm{pH}=7.4)$. Sections were incubated for 10 minutes to minimize dissociation. Determination of nonspecific binding was made in the presence of $10 \mu \mathrm{M}$ KML-29 (Chang et al., 2012). Slides were washed $4 \times$ 10 minutes in incubation buffer followed by two dips in deionized water. Sections were allowed to dry before scanning with a $\beta$-Imager (Biospacelab, Nesles la Vallee, France) for 2 hours. Quantitative analysis was performed using the M3 Vision (Biospacelab). Ex vivo MAGL labeling was expressed as the percentage of specific labeling in corresponding brain areas of vehicle-treated animals. The percentage of MAGL occupancy was plotted against time or dose using GraphPad Prism.

A similar procedure was used to measure CB1 occupancy on adjacent sections. Sections were incubated with $10 \mathrm{nM}\left[{ }^{3} \mathrm{H}\right] \mathrm{CP}-55940(164.9 \mathrm{Ci} /$ mmol) (Herkenham et al., 1990), and $10 \mu \mathrm{M}$ 1-(2,4-dichlorophenyl)-5-(4iodophenyl)-4-methyl- $N$-(1-piperidyl)pyrazole-3-carboxamide (Gatley et al., 1996) was used to determine nonspecific binding. Sections were incubated for 10 minutes to minimize dissociation.

In Vivo Microdialysis. A total of 51 male Sprague-Dawley rats (Charles River Laboratories, Hollister, CA) weighing approximately 300-400 g were used.

For hippocampal 2-AG measurements, a 14-mm guide cannula (MAB 2/6/9.14/IC; SciPro, Sanborn, NY) was surgically implanted into the hippocampus [from bregma: anterior-posterior $(\mathrm{AP})=-5.6 \mathrm{~mm}$, medial-lateral $(\mathrm{ML})=5.0 \mathrm{~mm}$, dorsal-ventral $=-3.0 \mathrm{~mm}$, and animals were allowed a 1-week recovery period prior to experimentation. On the morning of the experiment, 6-mm shaft/4-mm membrane probes (MAB 6.14.4 PES, 15-kDa molecular weight cutoff; SciPro) were slowly inserted into the cannula. The probes were perfused continuously with $10 \% \mathrm{HP}-\beta-\mathrm{CD} \mathrm{w} / \mathrm{v}$ in $1 \times$ artificial cerebrospinal fluid at a rate of $0.7 \mu \mathrm{l} / \mathrm{min}$ to optimize 2 -AG collection, as described previously (Buczynski and Parsons, 2010). Baseline collection began after an acclimatization period of $60-120$ minutes. Samples were collected every 30 minutes into a 96 -well plate at $1^{\circ} \mathrm{C}$. Each well contained $29 \mu \mathrm{l}$ of acetonitrile to help retard 2-AG isomerization in the dialysate. Test compounds or vehicle were administered intraperitoneally, and collection continued for 150 minutes. Dialysis samples were analyzed for 2-AG by LC (Shimadzu LC-30AD with CBM-20A system controller) with MS/MS detection. A Kinetex (Phenomenex, Torrance, CA) $1.7 \mu \mathrm{m}$ XB-C18 $100 \AA$, $2.1 \times 100 \mathrm{~mm}$ ultra-HPLC column was used with a mobile phase containing a mixture of $0.1 \%$ formic acid in water (solvent $\mathrm{A}$ ) and $0.1 \%$ formic acid in acetonitrile (solvent $\mathrm{B}$ ). The mobile phase was held at an A:B ratio of 80:20 for 1.5 minutes. The step gradient was quickly changed for 2 minutes to an A:B ratio of 30:70; slowly changed over the next 5.5 minutes to an $\mathrm{A}: \mathrm{B}$ ratio of $25: 75$; and then quickly changed to A:B ratio of 5:95 in 0.5 minutes, held for 2 minutes, and then returned to starting conditions. The total run time was 12.5 minutes, and the flow rate was $0.35 \mathrm{ml} / \mathrm{min}$. MS/MS detection was performed on a SCIEX $6500+$ Q-trap (SCIEX, Framingham, MA) in the positive ion mode by multiple reaction monitoring $(\mathrm{MH}+$ /daughter was $379.2 \rightarrow$ $287.3 \mathrm{~m} / \mathrm{z}$ ). The detection limit for $2-\mathrm{AG}$ was $0.2 \mathrm{pg} / 10 \mu \mathrm{l}$.

For cortical norepinephrine (NE) measurements, a 4-mm guide cannula was surgically implanted into the medial prefrontal cortex (from bregma: $\mathrm{AP}=3.2 \mathrm{~mm}, \mathrm{ML}=1.0 \mathrm{~mm}$, dorsal-ventral $=-1.0$ $\mathrm{mm}$ ), and animals were allowed to recover for 1 week prior to experimentation. On the evening before the experiment, 4-mm shaft/ 4-mm membrane probes (AJ-4-04, 50-kDa molecular weight cutoff; Amuza, San Diego, CA) were perfused continuously with $1 \times$ artificial cerebrospinal fluid at a rate of $1.0 \mu \mathrm{l} / \mathrm{min}$ and were slowly inserted into the cannula. On the morning of the experiment, dialysate samples were collected in a 96 -well plate at $4^{\circ} \mathrm{C}$ and a flow rate of $1.1 \mu \mathrm{l} / \mathrm{min}$ with a collection time of 30 minutes per sample. Test compounds or vehicle were intraperitoneally administered, and collection continued for 150 minutes. Collected samples were analyzed for NE by HPLC with electrochemical detection using an Eicompak CA-5ODS column ( $2.1 \mathrm{~mm}$ i.d. $\times 150 \mathrm{~mm}$; Amuza) with the graphite electrode potential set to $+450 \mathrm{mV}$ against an $\mathrm{Ag} / \mathrm{AgCl}$ reference electrode. The mobile phase consisted of $100 \mathrm{mM}$ sodium phosphate buffer containing $400 \mathrm{mg} / \mathrm{l}$ octanesulphonic acid, $50 \mathrm{mg} / \mathrm{l} \mathrm{EDTA}$, and 5\% (v/v) methanol $(\mathrm{pH}=6.0)$. The detection limit for NE was below $10 \mathrm{fg} / 10 \mu \mathrm{l}$.

In Vivo Electrophysiology. A total of 20 male Sprague-Dawley rats (Charles River Laboratories) weighing approximately 300-400 g were used.

Animals were anesthetized with isoflurane (5\% for induction, $1.5 \%$ for maintenance; $0.9 \mathrm{l} / \mathrm{min}$ flow rate) and head-fixed in a stereotaxic apparatus. Body temperature was maintained with a homeothermic heating pad, and respiration, heart rate, and pulse oximetry were continuously monitored. A $2.5-\mathrm{mm}$ piece of skull over the hippocampus was removed, and the exposed dura mater was carefully opened to allow for insertion of a concentric bipolar stimulating electrode (FHC, Bowdoin, ME) and tungsten recording microelectrode (World Precision Instruments, Sarasota, FL) into the Schaffer collateral pathway and pyramidal cell layer of CA1, respectively, using the following stereotaxic coordinates from bregma: stimulating electrode: $\mathrm{AP}=3.4 \mathrm{~mm}, \mathrm{ML}=2.75 \mathrm{~mm}$; recording electrode: $\mathrm{AP}=4.4 \mathrm{~mm}, \mathrm{ML}=2.25 \mathrm{~mm}$. Electrodes were initially inserted to a depth of $2 \mathrm{~mm}$ below the pial surface before evoked responses were obtained with test stimuli to aid in determining the final electrode placement.

Stimulation intensity was adjusted to evoke a 30\%-60\% maximal response, and subsequent stimulus pulses were continuously delivered at $0.33 \mathrm{~Hz}$. Signals were amplified and filtered $(1 \mathrm{~Hz}$ to $10 \mathrm{kHz}$, DAM80 bio-amplifier; World Precision Instruments), before collection (40-kHz sampling; PowerLab 16/35 data acquisition unit, LabChart Pro software; ADInstruments, Colorado Springs, CO). A 10-minute period of stable baseline recordings was obtained before compound or vehicle administration. Evoked responses were obtained for an additional 90 minutes thereafter. At the end of most recording sessions, the brain was removed and quickly frozen to determine 2AG and compound concentrations via LC-MS/MS. The evoked field potential slope was measured and normalized to the mean baseline slope for that animal. Results were then averaged across animals for each dosing group according to time relative to compound or vehicle dosing.

Sleep/Wake Recording and Analysis. Experiments were conducted in 15 male Sprague-Dawley rats weighing 350-450 g (Harlan Laboratories). Animals were surgically implanted with radiotelemetry probes [PhysioTel F40-EET; Data Sciences International (DSI), St. Paul, MN] to record locomotor activity and body temperature, with two epidural electrodes placed in the frontal and parietal cortex to record the EEG activity and in the dorsal nuchal muscles to record the electromyogram activity. Animals were allowed to recover for 2 weeks before being moved to a room housing receiving platforms to record wireless signals sent from the telemetry probes. EEG and electromyogram signals were recorded and digitized at a sampling rate of $250 \mathrm{~Hz}$, with high and low pass filters set at 0.5 and $60 \mathrm{~Hz}$, respectively, on a PC computer running Dataquest ART software (DSI). Polysomnographic wave forms were analyzed in 10-second periods and visually classified as wake, non-rapid eye movement (NREM) or rapid eye movement (REM) sleep using NeuroScore software (DSI). EEG gamma power during wake was determined by power spectral analysis using a Fast-Fourier transform with a frequency range of $30-60 \mathrm{~Hz}$ and was expressed as a percentage of the total power of the recorded signal.

The effects of JNJ-42226314 were assessed in two separate groups of animals ( 3 and $30 \mathrm{mg} / \mathrm{kg}$ ), with animals in each group also receiving 
TABLE 1

In vitro potency of JNJ-42226314, JZL-184, SAR-127303, and KML-29 to inhibit human, rat, and mouse MAGL using an in vitro [ $\left.{ }^{3} \mathrm{H}\right]$ 2-OG cleavage activity assay

Data represent mean \pm S.E.M. Number of independent experiments indicated in parentheses.

\begin{tabular}{|c|c|c|c|c|c|}
\hline Species & Source of MAGL & JNJ-42226314 IC $_{50}(\mathrm{nM})$ & JZL-184 $\mathrm{IC}_{50}(\mathrm{nM})$ & SAR-127303 $\mathrm{IC}_{50}(\mathrm{nM})$ & $\mathrm{KML}-29 \mathrm{IC}_{50}(\mathrm{nM})$ \\
\hline Human & HeLa cells & $1.13 \pm 0.05(>10)$ & $17.84 \pm 2.59$ & $11.17 \pm 0.79(>10)$ & $0.91 \pm 0.1(3)$ \\
\hline Human & PBMC & $1.88 \pm 0.41(6)$ & $24.01 \pm 3.78$ & $8.09 \pm 1.23$ & $0.88 \pm 0.07$ \\
\hline Mouse & Brain & $0.67 \pm 0.11(9)$ & $1.29 \pm 0.67(3)$ & $5.45 \pm 1.58(8)$ & $0.35 \pm 0.5(3)$ \\
\hline Rat & Brain & $0.97 \pm 0.12(10)$ & $57.76 \pm 10.32$ & $4.68 \pm 0.53(9)$ & $1.16 \pm 0.15(3)$ \\
\hline
\end{tabular}

a control vehicle dosing. A washout period of, at minimum, 3 days and, at maximum, 7 days was observed between JNJ-42226314 and vehicle treatments. In each study, JNJ-42226314 or vehicle was administered by intraperitoneal injection at 8:00 AM, 2 hours after the start of the "light phase," to correspond to the time of day in which the in vivo electrophysiology experiments were conducted. Signals were recorded for 10 hours afterward. Latency to NREM sleep was defined as the time interval between treatment and the first six consecutive NREM epochs, whereas REM sleep latency was defined as the time interval between treatment and the first two consecutive REM epochs. For each animal, total wake, NREM sleep, and REM sleep time and average wake gamma power were determined over successive 2-hour periods after dosing to provide enough time points for appropriate statistical analysis. Locomotor activity and body temperature were assessed in 1-hour periods. Results were averaged across animals and expressed as the mean \pm S.E.M. within each time interval.

Rat Complete Freund's Adjuvant-Induced Radiant Heat Hypersensitivity. To assess the ability of JNJ-42226314 to reverse complete Freund's adjuvant (CFA)-induced thermal hyperalgesia, baseline response latencies on a radiant heat paw stimulator were obtained before an intraplantar injection of $100 \mu \mathrm{l}(1 \mu \mathrm{g} / \mu \mathrm{l}) \mathrm{CFA}(1: 1$ CFA:saline) in 30 male Sprague-Dawley rats (250-350 g), as previously described (Parsons et al., 2015). Withdrawal responses that consisted of quick hind paw movements away from the stimulator were recorded. Paw movements associated with locomotion or a shifting of weight were not counted. Stimulus intensities evoking 10- to 15second baseline withdrawal latencies were used, with a maximum cutoff of 20 seconds. Hypersensitivity was evaluated 24 hours after CFA administration. Only rats that exhibited at least a $25 \%$ reduction in response latency from baseline (i.e., hyperalgesia) were included for further analysis. Blood samples and brains were removed from the rats immediately following the last behavioral measure and analyzed for the concentration of JNJ-42226314 as well as 2-AG.

Chronic Constriction Injury-Induced Cold Hypersensitivity Assay. To assess the ability of JNJ-42226314 to reverse chronic constriction injury (CCI)-induced cold hypersensitivity, four loose ligatures of 4-0 chromic gut were surgically placed around the left sciatic nerve of 36 male Sprague-Dawley rats (175-325 g) under inhalation anesthesia, as described by Bennett and Xie (1988). Fifteen to 35 days following CCI surgery, animals were placed in elevated observation chambers consisting of wire mesh floors. A series of five applications of acetone $(0.10 \mathrm{ml} /$ application) was gently sprayed onto the underside of the paw through the mesh floor using a multidose syringe device. Positive responses consisted of a rapid or protracted withdrawal or lifting of the paw. The percentage of positive responses from the five trials represented the animal's overall response, which was then averaged within each treatment group. Percent inhibition was then calculated as:

$$
\begin{aligned}
\% \text { Inhibition }= & {[1-(\text { responses after JNJ-42226314 treatment } /} \\
& \text { responses after vehicle treatment })] \times 100 .
\end{aligned}
$$

Statistics. Results are given as the mean \pm S.E.M. To assess whether the data deviated from normality, we employed the Shapiro and Wilk's W test for normality. Data across all experimental replicates for each dose and each time point were tested, with a false discovery rate correction to account for the multiple tests. Treatment effects on field excitatory postsynaptic potentials (fEPSPs), 2-AG/ norepinephrine microdialysis area under the curve (AUC) measurements, and CCI-induced cold allodynia were analyzed by one-way ANOVA followed by Dunnett's multiple comparisons post hoc test to determine significance versus vehicle. Paired $t$ tests were used to assess treatment effects on sleep latencies. Time course data from experiments assessing treatment effects on 2-AG microdialysis, sleep/wake duration, locomotor activity, body temperature, gamma power, and CFA/CCI-induced pain hypersensitivity were analyzed via two-way repeated measures ANOVA (treatment $\times$ time as factors) and followed by Bonferroni multiple comparisons post hoc test to determine significance versus vehicle at a given time point. Norepinephrine microdialysis time course data were analyzed with a Linear Mixed-Effects model to compare treatments effects over time with "Treatment" and "Time" as fixed effects and "animal" as a random effect. The information derived from the model was used to make pairwise treatment comparisons with false discovery rate adjusted $P$ values. Differences at $P<0.05$ were considered statistically significant. ANOVA and $t$ tests were performed with GraphPad Prism, version 7.0. Linear Mixed-Effects
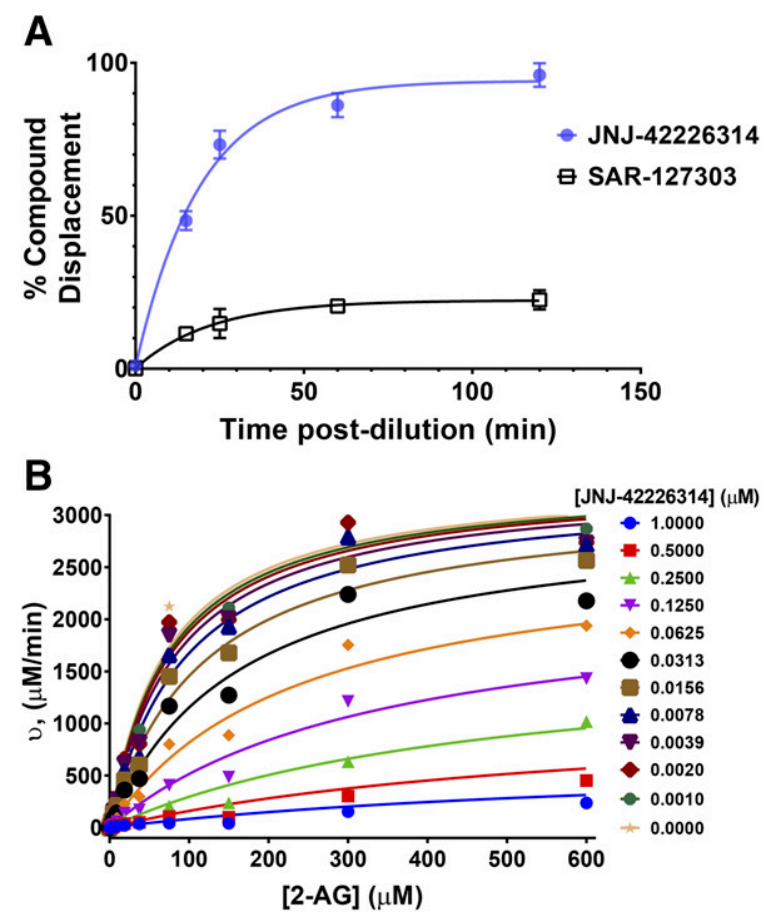

Fig. 2. In vitro mode of action of JNJ-42226314. (A) Displacement of JNJ-42226314 and SAR-127303 by $\left[{ }^{3} \mathrm{H}\right]$ SAR-127303 in human brain membrane homogenates. Unlabeled compounds were equilibrated with brain membranes and then diluted in $\left[{ }^{3} \mathrm{H}\right]$ SAR-127303 to measure dissociation rates over time. (B) Plots of MAGL reaction velocity (recombinant human MAGL) against substrate concentration. The initial rates obtained at different substrate concentrations were analyzed via least-squares analysis according to eq. 1 (Materials and Methods), and the experimental initial rates are plotted as a function of 2-AG concentration with the solid lines representing the theoretical values calculated from the least-squares analysis. 
TABLE 2

In vitro displacement times $\left(\mathrm{t}_{1 / 2}\right)$ and dissociation rate constants $\left(\mathrm{k}_{\mathrm{d}}\right)$ of JNJ-42226314 with MAGL from human, mouse, and rat brain membranes

Values are expressed as the average \pm S.D. $(N=3$ experiments $)$.

\begin{tabular}{lcc}
\hline MAGL & $\mathrm{t}_{1 / 2}(\min )$ & $\mathrm{k}_{\mathrm{d}}\left(\mathrm{min}^{-1}\right)$ \\
\hline Human & $11.4 \pm 2.2$ & $0.062 \pm 0.013$ \\
Mouse & $27.6 \pm 5.5$ & $0.026 \pm 0.005$ \\
Rat & $27.2 \pm 2.1$ & $0.026 \pm 0.002$ \\
\hline
\end{tabular}

analysis was performed with $\mathrm{R}$ software, version 3.5.0 (https://www. r-project.org/).

\section{Results}

JNJ-42226314 Is a Potent Inhibitor of MAGL Across Species. Inhibition of native human MAGL in HeLa cells or human PBMCs by JNJ-42226314 was measured using an in vitro assay measuring cleavage of radioactive substrate $\left[{ }^{3} \mathrm{H}\right]$
2-OG (Table 1). MAGL is the predominant serine hydrolase (approximately 90\%) in HeLa cells and homogenates thereof Dinh et al. (2004). The blockade of MAGL hydrolytic activity by JNJ-42226314, JZL-184, or SAR-127303 (10 $\mu \mathrm{M})$ corresponds to $>95 \%$ of the blockade achieved by the pan-hydrolase inhibitor methyl arachidonyl fluorophosphonate $(10 \mu \mathrm{M})$. By comparison, the $\alpha / \beta$ hydrolase domain containing 6 inhibitor $N$-methyl- $N$-[[3-(4-pyridinyl)phenyl]methyl]-carbamic acid 4' (aminocarbonyl)[1,1'-biphenyl]-4-yl ester (10 $\mu \mathrm{M})$ lacked significant effect in this assay (unpublished data). Substrate exhaustion under standard assay conditions was experimentally ruled out. Secondary washes were applied to the charcoal filter to show the total amount of $\left[{ }^{3} \mathrm{H}\right] 2$-OG hydrolyzed under standard assay conditions. Less than $10 \%$ of the labeled substrate was hydrolyzed, thereby ruling out reagent exhaustion artifacts.

The potency of JNJ-42226314 to inhibit human MAGL from HeLa cells or from human PBMCs was comparable and in the
A
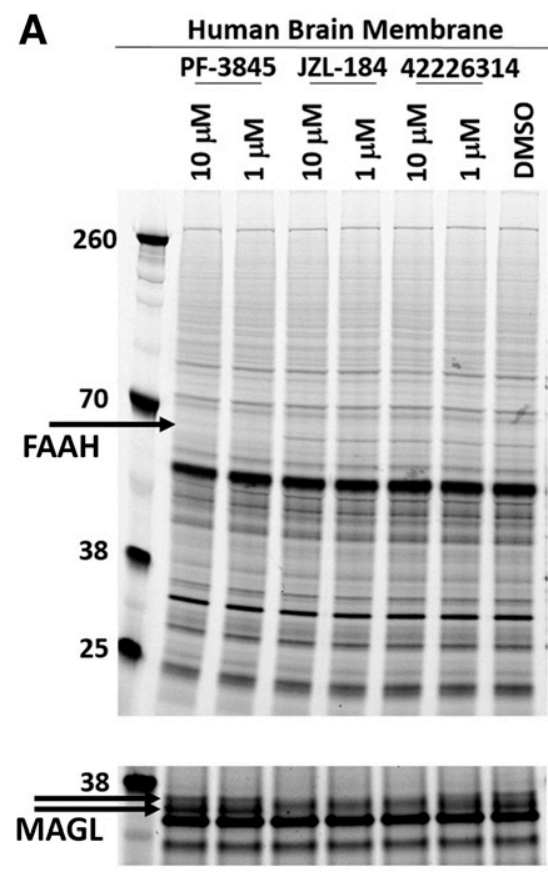

C

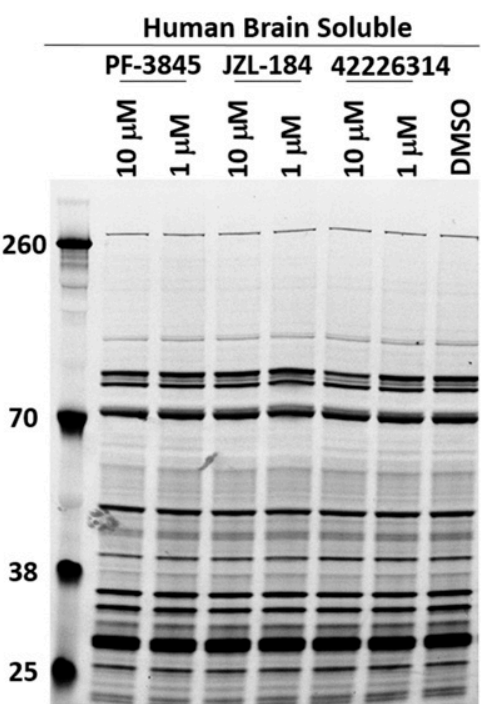

B

Human Liver Membrane

PF-3845 JZL-184 42226314
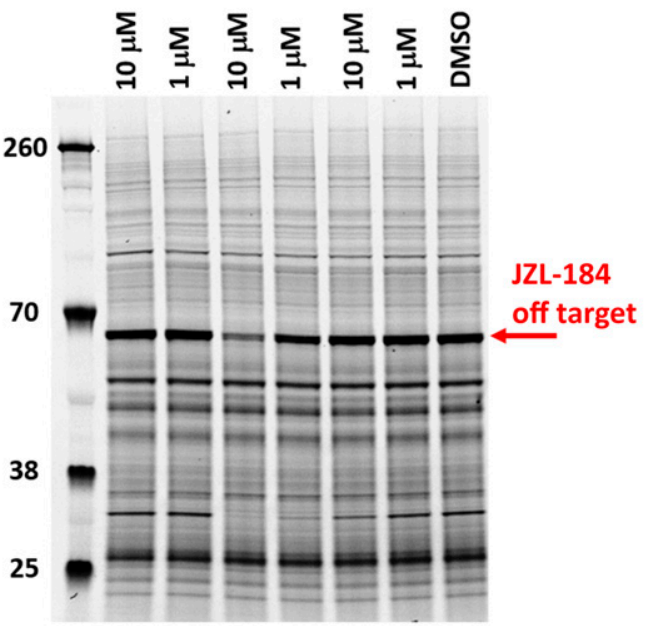

38

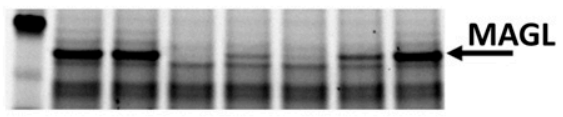

D

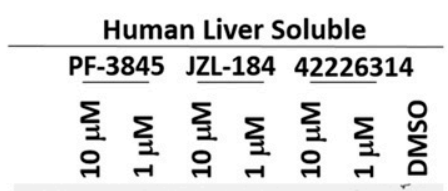

$260-$

JZL-184 off target(s)
Fig. 3. Selectivity profiling of JNJ-42226314 by competitive ABPP after treatment with PF-3845 (1 or $10 \mu \mathrm{M})$, JZL-184 (1 or $10 \mu \mathrm{M})$, JNJ-42226314 (1 or $10 \mu \mathrm{M})$, or vehicle (DMSO). (A) Gel profiles of FP-Rh labeled membrane serine hydrolases from human brain and (B) human liver. MAGL bands were better resolved by a longer electrophoresis until the $25-\mathrm{kDa}$ protein marker was running off the gel (panels at the bottom of A and B). (C) Gel profiles of FP-Rh labeled soluble serine hydrolases from human brain and (D) human liver. FAAH, MAGL (black), and JZL-184 off-targets (red) are indicated where clearly resolved.

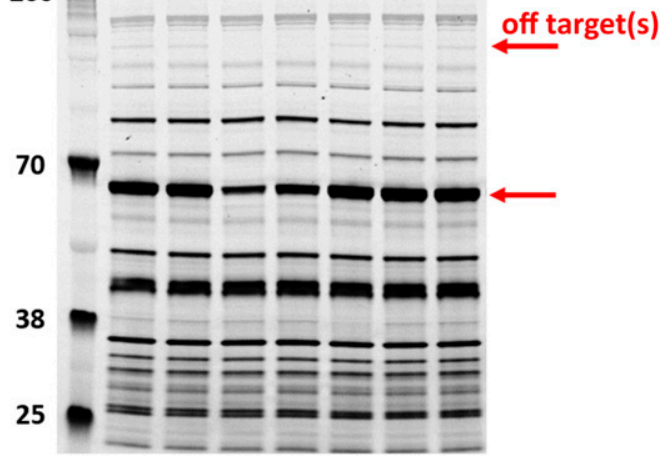


A
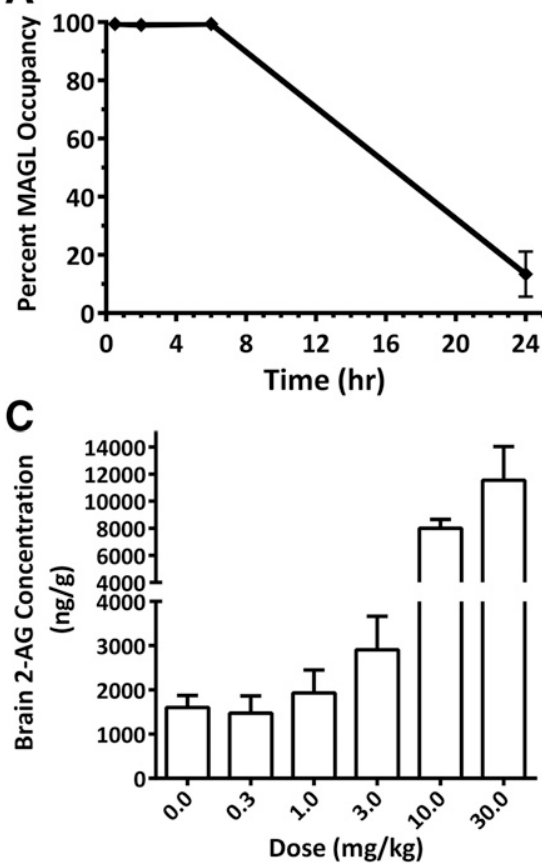

B

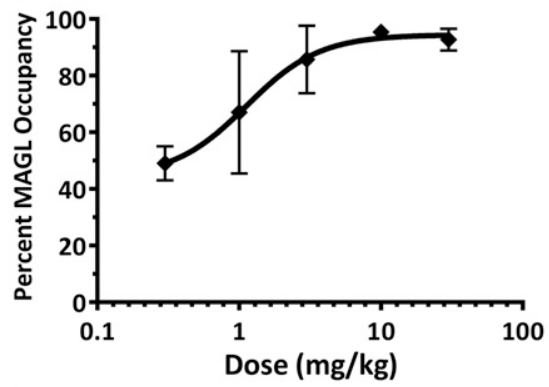

D

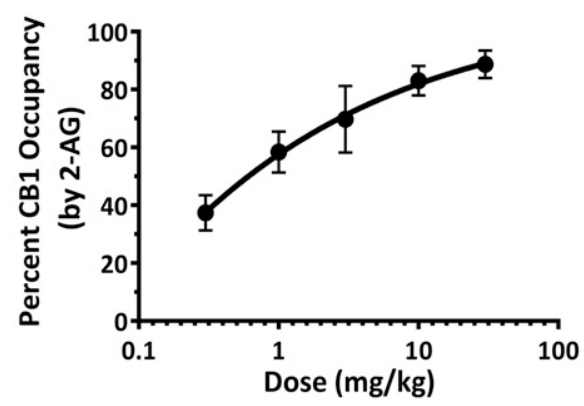

Fig. 4. Rat ex vivo target occupancy profile of JNJ-42226314. (A) Time course of MAGL occupancy in rat hippocampus by JNJ-42226314 following $30 \mathrm{mg} / \mathrm{kg}$ i.p. administration. Dosedependent effects of systemic JNJ-42226314 30 minutes after intraperitoneal administration on (B) MAGL occupancy, (C) brain 2-AG levels, and (D) CB1 occupancy by 2-AG. $N=3$ per time point or dose. Data are presented as the mean \pm S.E.M. low nanomolar range. No speciation was identified, as shown by the comparable potency to inhibit MAGL in mouse and rat brain (Table 1). SAR-127303 and KML-29 exhibited similar potency to JNJ-42226314 in inhibiting human, rat, and mouse MAGL. As previously reported (Pan et al., 2009), the covalent MAGL inhibitor JZL-184 was a more potent inhibitor of human and mouse MAGL than rat MAGL (Table 1).

JNJ-42226314 Is a Reversible MAGL Inhibitor and Inhibits MAGL Competitively with Respect to the 2-AG Substrate. Displacement of JNJ-42226314 bound to human brain membranes was shown using $\left[{ }^{3} \mathrm{H}\right]$ SAR-127303. For simplicity, compound displacement is reported here as the $t_{1 / 2}$, which equals $\ln (2) / \mathrm{k}_{\mathrm{d}}$. Time-dependent displacement of JNJ42226314 occurred with $\mathrm{a} \mathrm{t}_{1 / 2}$ of $12 \pm 2$ minutes at $37^{\circ} \mathrm{C}$, indicative of reversible binding/inhibition by this compound (Fig. 2A). In contrast, SAR-127303, which forms a covalent bond with MAGL, was irreversible, as it was not displaced by $\left[{ }^{3} \mathrm{H}\right]$ SAR-127303. Rat and mouse dissociation rates for JNJ42226314 were very similar and approximately half that of human (Table 2). Inhibition of recombinant human MAGL by JNJ-42226314 was also demonstrated to be reversible by following the recovery of enzyme activity from a preincubation mixture of MAGL and JNJ-42226314 after jump dilution (unpublished data).

The mode of action for the inhibition of human MAGL by JNJ42226314 was then studied in detail utilizing a recombinant human enzyme generated as described in the Materials and Methods section. Initial reaction rates were obtained in the presence of different concentrations of substrate and inhibitor to determine the mode of MAGL inhibition by JNJ-42226314. The results were evaluated by global fit through a least-squares analysis according to eq. 1 (see Materials and Methods). The experimental and theoretical values calculated according to the global fit are shown in Fig. 2B. The $\alpha$ value from the fit to eq. 1 is large $(13 \pm 6)$, indicating competitive inhibition of MAGL by JNJ42226314. The kinetic parameters calculated from the leastsquares analysis according to eq. 1 were: $V_{\max }=3.37 \pm 0.07 \mu \mathrm{M} /$ $\min ; K_{\mathrm{m}}=71 \pm 5 \mu \mathrm{M}$; and $K_{\mathrm{i}}=0.020 \pm 0.003 \mu \mathrm{M}$. These results represent the mechanistic understanding of JNJ-42226314 obtained through initial rate analysis (see Materials and Methods, Inhibition Kinetics). The full biochemical and biophysical characterization of the inhibitor-enzyme interaction will be the subject of a future publication.

JNJ-42226314 Is Highly Selective for MAGL. Selectivity for JNJ-42226314 against the serine hydrolase superfamily was assessed at 1 and $10 \mu \mathrm{M}$ by competitive ABPP using membrane and soluble proteomes prepared from human, mouse, and rat tissues (Liu et al., 1999; Leung et al., 2003). For comparison, the covalent MAGL inhibitor JZL-184 (Long et al., 2009a) was included. The covalent FAAH inhibitor PF3845 (Ahn et al., 2009) was also included for confirmation of FAAH bands. The treated proteomes were resolved on

\section{TABLE 3}

Level of MAGL occupancy in rat hippocampus, plasma and brain compound exposure and brain 2-AG assessed at the indicated timepoints after systemic administration of JNJ-42226314 (30 mg/kg, i.p.)

Results shown are means \pm S.E.M. $(N=3)$. Values reported without S.E.M. indicate JNJ-42226314 levels were BLLOQ for at least one animal in that group.

\begin{tabular}{lcccc}
\hline Time $(\mathrm{h})$ & Brain $(\mathrm{ng} / \mathrm{g})$ & Plasma $(\mathrm{ng} / \mathrm{ml})$ & Brain 2-AG $(\mathrm{ng} / \mathrm{g})$ & MAGL Occupancy $(\%)$ \\
\hline 0.5 & $6625 \pm 1500$ & $12,212 \pm 3243$ & $13,920 \pm 700$ & $99 \pm 1$ \\
2 & $3465 \pm 1403$ & $4245 \pm 1379$ & $12,370 \pm 3026$ & $99 \pm 1$ \\
6 & $431 \pm 100$ & $836 \pm 205$ & $5489 \pm 447$ & $99 \pm 0.4$ \\
24 & BLLOQ & 3 & $1160 \pm 53$ & $13 \pm 8$
\end{tabular}

BLLOQ, below the lowest level of quantification $(1 \mathrm{ng} / \mathrm{ml})$. 
TABLE 4

Dose dependency of MAGL occupancy measured in mouse hippocampus after intraperitoneal administration of JNJ-42226314

Corresponding plasma and brain compound exposure and brain 2-AG at 30 min are also shown. Results are mean \pm S.E.M. $(N=3)$. Values reported without S.E.M. indicate JNJ-42226314 levels were below the lowest level of quantification for at least one animal in that group.

\begin{tabular}{lcccc}
\hline Dose (i.p.) & Brain (ng/g) & Plasma (ng/ml) & $\begin{array}{c}\text { Brain 2-AG } \\
(\mathrm{ng} / \mathrm{g})\end{array}$ & $\begin{array}{c}\text { MAGL } \\
\text { Occupancy \% }\end{array}$ \\
\hline 0.1 & $43 \pm 38$ & $10 \pm 2$ & $456 \pm 40$ & $0 \pm 0$ \\
0.3 & 16 & 26 & $535 \pm 93$ & $12 \pm 12$ \\
1 & 82 & $131 \pm 67$ & $1164 \pm 379$ & $58 \pm 29$ \\
3 & $131 \pm 41$ & $347 \pm 168$ & $2401 \pm 509$ & $95 \pm 3$ \\
10 & $925 \pm 54$ & $2811 \pm 164$ & $8425 \pm 520$ & $98 \pm 1$ \\
30 & $2180 \pm 968$ & $5360 \pm 2407$ & $8363 \pm 2460$ & $98 \pm 2$ \\
\hline
\end{tabular}

4\%-12\% gradient gels to visualize the maximum number of serine hydrolases and better assess broad selectivity from human brain (Fig. 3A) and liver (Fig. 3B) membrane proteomes as well as from human brain (Fig. 3C) and liver (Fig. 3D) soluble proteomes. MAGL was more clearly resolved by a longer electrophoresis until the $25-\mathrm{kDa}$ protein marker was running off the gel (panels at the bottom of Fig. 3, A and B). JNJ-42226314 showed partial and complete inhibition of MAGL at 1 and $10 \mu \mathrm{M}$, respectively, with no off-targets in the human brain and liver membrane proteomes. JNJ-42226314 also showed no off-targets in human brain and liver soluble proteomes. JZL-184 was also highly selective in human brain proteomes but showed off-targets at $10 \mu \mathrm{M}$ corresponding to a band at $\sim 65 \mathrm{kDa}$ in human liver proteomes. PF-3845 completely inhibited FAAH in human brain membrane proteomes at 1 and $10 \mu \mathrm{M}$ and showed no off-targets in human brain and liver proteomes, as previously reported (Ahn et al., 2009). The high selectivity observed for JNJ42226314 was maintained across species, because offtargets were also not observed in rat and mouse proteomes (Supplemental Figs. 1 and 2, respectively). Similarly, JZL184 was highly selective in brain proteomes but showed offtargets in liver proteomes derived from rat and mouse.

To further assess the specificity of JNJ-42226314 relative to other unrelated targets, it was evaluated in a panel of 50 binding assays for ion channels and receptors, including CB1 and CB2. At $10 \mu \mathrm{M}$, JNJ-42226314 displayed binding to four targets by greater than 50\%: rat kappa opioid receptor, rat $5-\mathrm{HT}_{1 \mathrm{~B}}$ receptor, rat chloride ion channel, and human dopamine transporter. However, in follow-up studies to assess functional activity in cellular assays, JNJ-42226314 produced no functional agonist or antagonist activity at the rat kappa opioid receptor. JNJ-42226314 at $10 \mu \mathrm{M}$ behaved as a weak partial agonist of the rat $5-\mathrm{HT}_{1 \mathrm{~B}}$ receptor (50\% of control agonist response) and inhibited dopamine uptake by $35 \%$, respectively.

Taken together, these data demonstrate that JNJ-42226314 is highly selective for MAGL relative to other mammalian serine hydrolases and other unrelated targets including receptors and ion channels.

Systemic Administration of JNJ-42226314 Engages MAGL and CB1. Time and dose dependency of MAGL occupancy in vivo, as assessed by ex vivo binding autoradiography of $\left[{ }^{3} \mathrm{H}\right]$ SAR-127303 in rat hippocampus brain tissue sections after intraperitoneal administration, are shown in Fig. 4.

Intraperitoneal administration of JNJ-42226314 (30 mg/kg) inhibited $\left[{ }^{3} \mathrm{H}\right]$ SAR-127303 binding in the rat hippocampus, indicating brain penetration. JNJ-42226314 quickly reached maximal MAGL occupancy at 30 minutes and remained at this level for at least 8 hours before declining to approximately $13 \%$ occupancy at 24 hours (Fig. 4A). Corresponding compound plasma and brain concentrations, as well as brain 2-AG levels, are presented in Table 3. Overall, there was a general association between 2-AG and compound concentration, because 2-AG levels decreased along with JNJ-42226314 plasma/brain levels.

For the rat dose-response study, MAGL occupancy was measured 30 minutes after drug administration (Fig. 4B). This time point corresponded with the maximum measured plasma drug concentration $\left(t_{\max }\right)$ of JNJ-42226314 after the $30 \mathrm{mg} / \mathrm{kg}$ dose (Table 3 ). At the lower dose tested in this study $(0.3 \mathrm{mg} / \mathrm{kg}), 49 \%$ MAGL occupancy was measured, corresponding to a plasma concentration of $75 \mathrm{ng} / \mathrm{ml}$ and a brain concentration of $42 \mathrm{ng} / \mathrm{g}$. Dosedependent increases in brain 2-AG levels were observed (Fig. 4C), which were associated with measurable CB1 occupancy (Fig. 4D). Maximal CB1 occupancy ( 80\%) was reached at $30 \mathrm{mg} / \mathrm{kg}$, as assessed by ex vivo autoradiography with $\left[{ }^{3} \mathrm{H}\right] \mathrm{CP}-55940$.

A mouse dose-response study was also performed to assess any species-specific differences in target engagement or compound exposure. MAGL occupancy was measured at the 30-minute time point (Table 4$)$. The measured $50 \%$ effective dose $\left(\mathrm{ED}_{50}\right)$ was $0.5 \mathrm{mg} / \mathrm{kg}$ (95\% confidence interval, $0.4-0.7 \mathrm{mg} / \mathrm{kg})$. The $\mathrm{ED}_{50}$ dose of $0.5 \mathrm{mg} / \mathrm{kg}$ in this study corresponded to a calculated plasma exposure of $51 \mathrm{ng} / \mathrm{ml}$ and a brain exposure of $30 \mathrm{ng} / \mathrm{g}$, similar to what was observed in the rat.

JNJ-42226314 Dose-Dependently Elevates Hippocampal 2-AG In Vivo. The effect of systemic JNJ-42226314 administration on brain 2-AG levels was assessed in the hippocampus of awake, behaving rats via in vivo microdialysis. Both 3 and $30 \mathrm{mg} / \mathrm{kg}$ (i.p.) evoked time- and dosedependent elevations in hippocampal 2-AG levels relative to vehicle controls $\left[\mathrm{F}_{(16,184)}=14.16, P<0.001\right]$, with 2 -AG concentrations peaking at approximately $300 \%(3 \mathrm{mg} / \mathrm{kg})$ and $500 \%(30 \mathrm{mg} / \mathrm{kg})$ of vehicle control levels 60 minutes after compound administration (Fig. 5A). Analysis of total AUC for the entire 150-minute postdosing collection period revealed significant treatment effects of JNJ-42226314 on 2-AG levels $\left[\mathrm{F}_{(2,23)}=19.37, P<0.001\right]$ (Fig. 5B).

JNJ-42226314 Dose-Dependently Inhibits Evoked Synaptic Responses in CA1 In Vivo. In vivo electrophysiological recordings from hippocampal CA1 in anesthetized rats revealed a dose-dependent depression of evoked fEPSPs produced by systemic JNJ-42226314 administration (Fig. 5C). Analysis of fEPSP slope 90 minutes postdosing revealed significant dose effects of JNJ-42226314 $\left[\mathrm{F}_{(2,17)}=13.84, P<0.001\right]$, with fEPSP slope being significantly reduced relative to vehicletreated controls after $30 \mathrm{mg} / \mathrm{kg}$ (78\% of predosing baseline vs. $95 \%$ of predosing baseline, respectively) but not $3 \mathrm{mg} / \mathrm{kg}(91 \%$ of baseline vs. $95 \%$ of baseline) dosing (Fig. 5D). At the end of most recording sessions, brains were rapidly removed and frozen for later determination of 2-AG and JNJ-42226314 concentrations. Analysis of whole-brain homogenates revealed a positive correlation between 2-AG levels and fEPSP inhibition (Fig. 5E; $\mathrm{EC}_{50}=7.1 \mu \mathrm{g} / \mathrm{g} 2-\mathrm{AG} ; \mathrm{R}^{2}=0.70$ ) as well as between JNJ-42226314 concentration and fEPSP inhibition (Fig. 5F; $\mathrm{EC}_{50}=251 \mathrm{ng} / \mathrm{g}$ JNJ-42226314; $\left.\mathrm{R}^{2}=0.69\right)$. Compared with the rat brain 2-AG and JNJ-42226314 concentration data from the MAGL occupancy study (Table 4), these EC $_{50}$ values are 
A

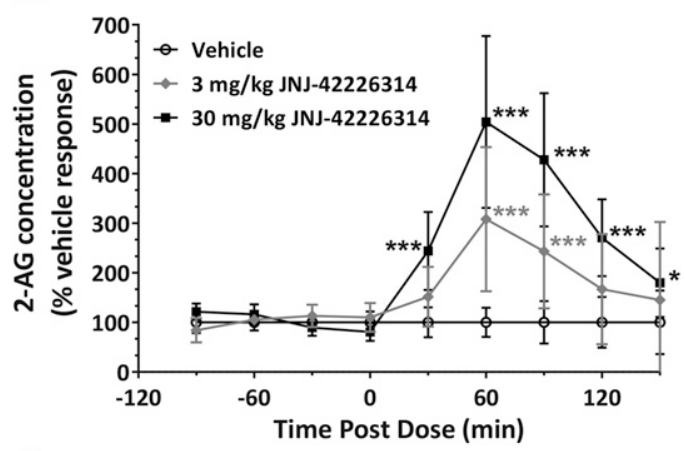

C

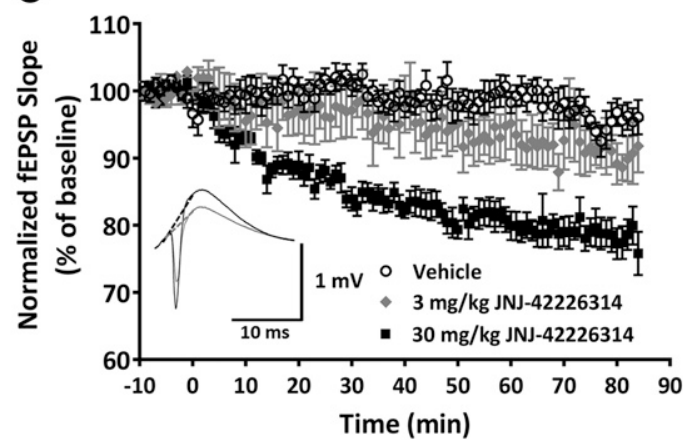

E

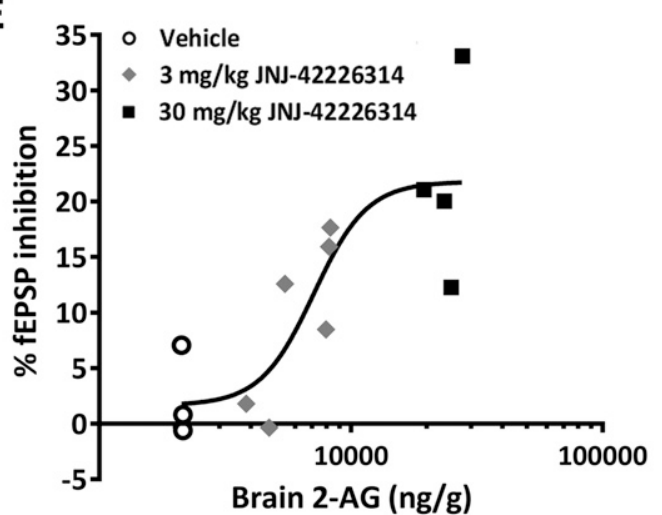

B
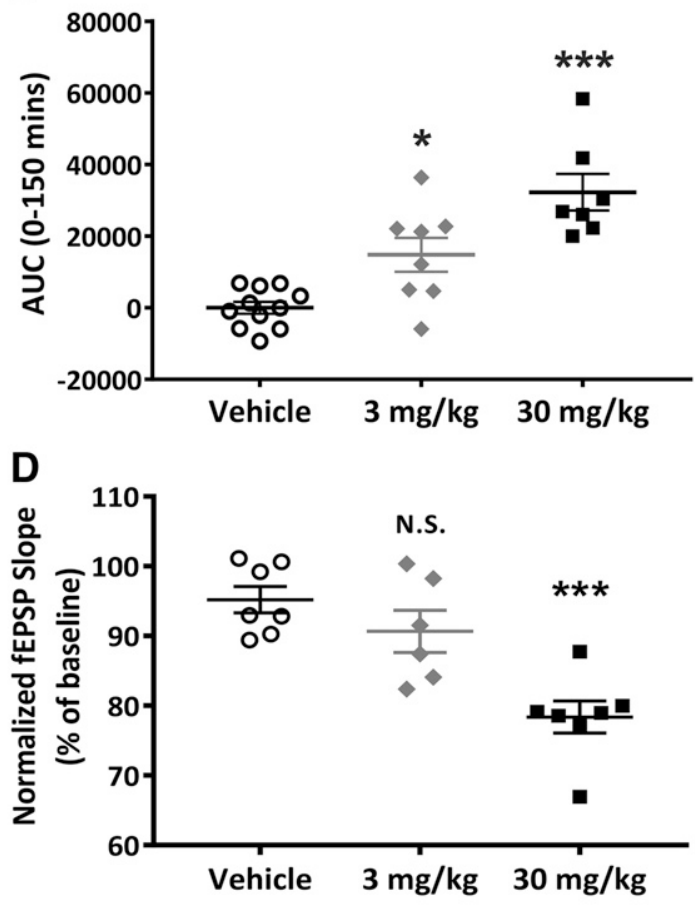

$\mathbf{F}$

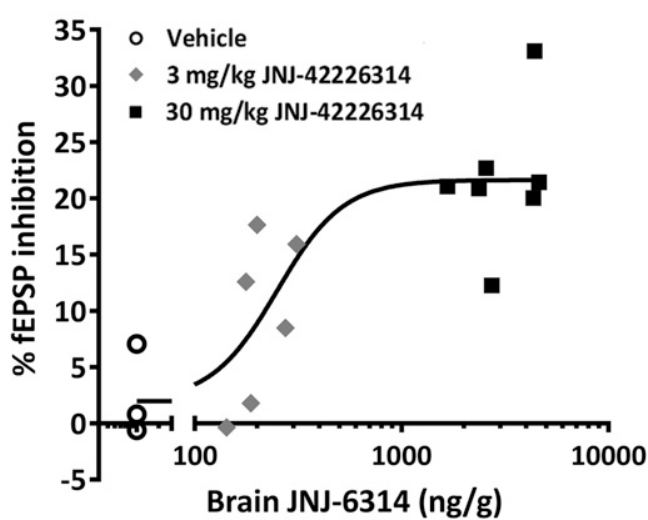

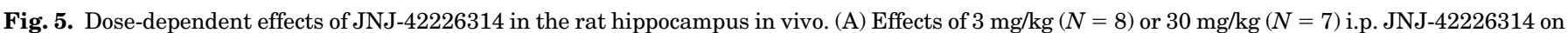

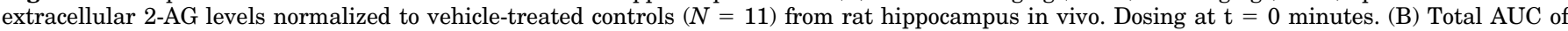

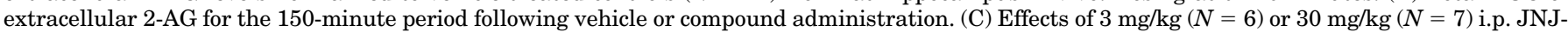

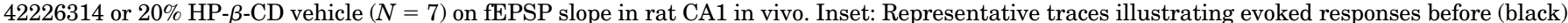

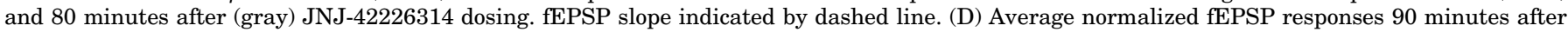

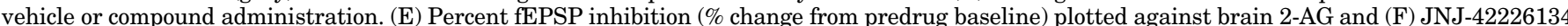

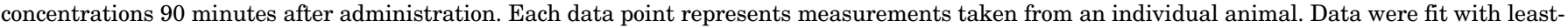
squares fit nonlinear regression curves. (A, B, and D): N.S., not significant. $* P<0.05$, and $* * * P<0.001$ vs. vehicle.

within the range of concentrations that correspond to approximately $90 \%$ MAGL occupancy.

JNJ-42226314 Dose-Dependently Prolongs Wakefulness in Rats. Acute effects of JNJ-42226314 on sleep-wake patterns were investigated in rats. Relative to vehicle, intraperitoneal administration of $30 \mathrm{mg} / \mathrm{kg}$ JNJ-42226314 2 hours after onset of the light (rest) phase significantly increased total wake time for up to 8 hours afterward $\left[\mathrm{F}_{(4,28)}=9.143\right.$, $P<0.001$ ], whereas total wake time was only elevated for 2 hours following a $3 \mathrm{mg} / \mathrm{kg}$ dose of JNJ-42226314 $\left[\mathrm{F}_{(4,24)}=\right.$ 4.032, $P=0.012$ ] (Fig. 6A). Wake gamma power, a measure associated with working memory and attention, was not significantly affected during the 10-hour period following $3 \mathrm{mg} / \mathrm{kg}$ JNJ-42226314 administration $\left[\mathrm{F}_{(1,59)}=0.002\right.$,
$P=0.96]$; however, $30 \mathrm{mg} / \mathrm{kg}$ significantly reduced gamma power $\left[\mathrm{F}_{(1,7)}=7.33, P=0.03\right]$ (Fig. 6B)

Dose-dependent effects on the duration of NREM and REM sleep were also observed over the 10-hour postdosing period. A dose of $3 \mathrm{mg} / \mathrm{kg} \mathrm{JNJ}-42226314$ decreased the duration of NREM sleep versus vehicle for 2 hours after dosing $\left[\mathrm{F}_{(4,24)}=\right.$ $3.15, P=0.03$ ], whereas this measure was significantly reduced for up to 8 hours after $30 \mathrm{mg} / \mathrm{kg}$ administration $\left[\mathrm{F}_{(4,28)}=9.85, P<0.001\right]$ (Fig. 6C). Likewise, REM sleep was almost entirely abolished for the 10-hour period following $30 \mathrm{mg} / \mathrm{kg}$ JNJ-42226314 [F $\left.{ }_{(4,28)}=8.73, P<0.001\right]$ but was much more moderately affected following $3 \mathrm{mg} / \mathrm{kg}$ dosing $\left[\mathrm{F}_{(4,24)}=3.05, P=0.04\right]$ with a nonsignificant reduction in REM sleep during the first 2 hours after dosing (Fig. 6D). 
A

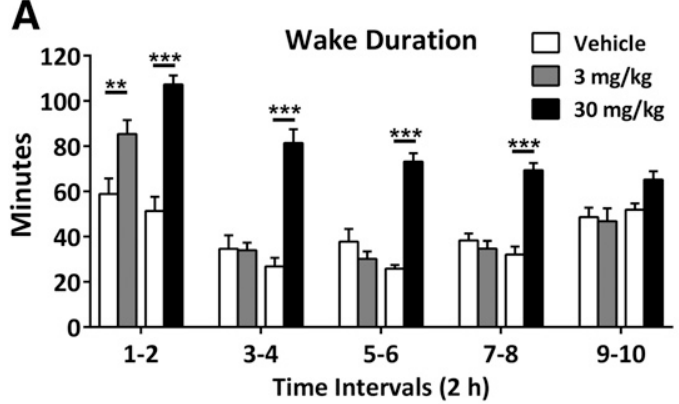

C

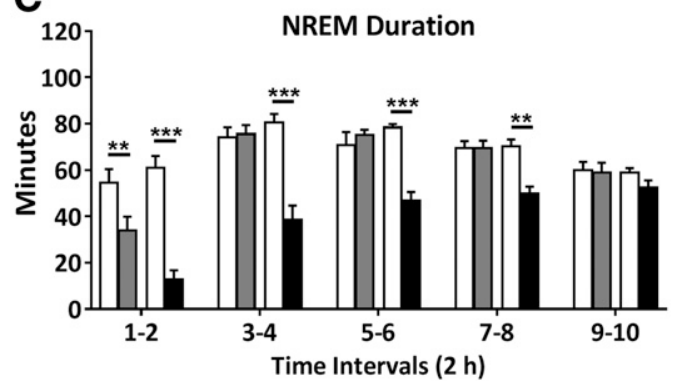

B

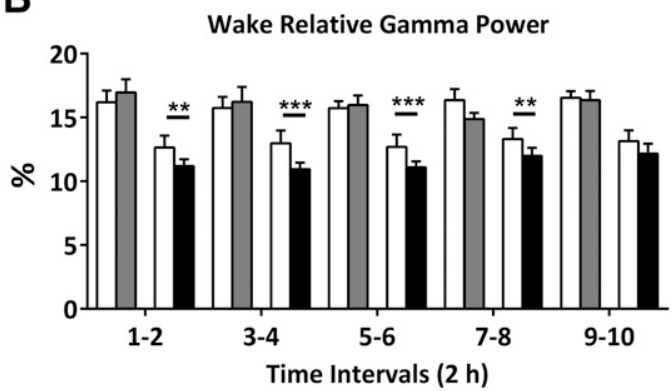

D

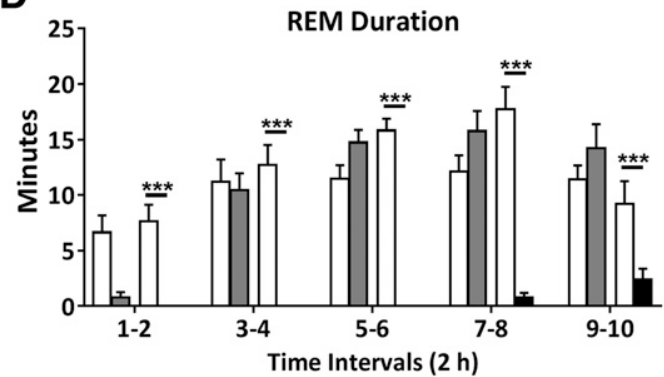

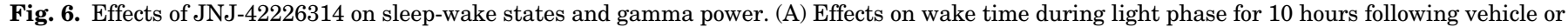

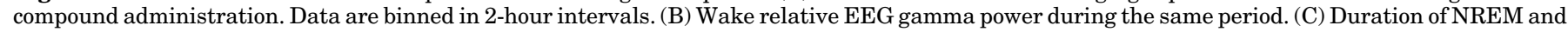

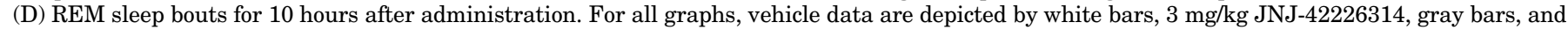

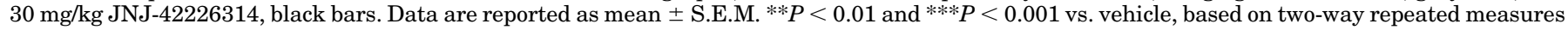
ANOVA followed by Bonferroni's multiple comparison post hoc test. $N=7$ (vehicle vs. $3 \mathrm{mg} / \mathrm{kg}$ ) or 8 (vehicle vs. $30 \mathrm{mg} / \mathrm{kg}$ ) rats.

Similarly, both 3 and $30 \mathrm{mg} / \mathrm{kg}$ doses of JNJ-42226314 increased the latency to the first bouts of NREM and REM sleep, though the effects were more pronounced at $30 \mathrm{mg} / \mathrm{kg}$ for both NREM ( $3 \mathrm{mg} / \mathrm{kg}$ : $68.1 \pm 12.5$ minutes, vehicle: $31.2 \pm$ 5.3 minutes, $P<0.05$ via paired $t$ test; $30 \mathrm{mg} / \mathrm{kg}: 104.1 \pm 15.3$ minutes, vehicle: $29.4 \pm 2.9$ minutes, $P<0.001$ via paired $t$ test) and REM ( $3 \mathrm{mg} / \mathrm{kg}: 135.2 \pm 15.6$ minutes, vehicle: 64.9 \pm 12.3 minutes, $P<0.05$ via paired $t$ test; $30 \mathrm{mg} / \mathrm{kg}: 487.7 \pm$ 28.0 minutes, vehicle: $68.6 \pm 12.5$ minutes, $P<0.001$ via paired $t$ test) latencies.

Overall locomotor activity and body temperature were also measured during this period to determine if JNJ-42226314 induced hypolocomotive and hypothermic effects characteristic of direct CB1 agonists (Wiley et al., 1998). Neither dose of JNJ-42226314 decreased locomotor activity (Supplemental Fig. 3); however, a brief increase in locomotion was observed during the 1st hour after dosing in $3 \mathrm{mg} / \mathrm{kg}$ JNJ-42226314-treated rats. A delayed hypothermia, beginning around 3 hours after dosing and persisting through the end of the 10-hour observation period, occurred in rats treated with $30 \mathrm{mg} / \mathrm{kg} \mathrm{JNJ}-$ 42226314. Significant hypothermic effects were transiently observed at the 6 -hour time point after treatment with $3 \mathrm{mg} / \mathrm{kg}$ JNJ-42226314.

JNJ-42226314 Dose-Dependently Increases Norepinephrine Release in Cortex. In vivo microdialysis was employed to measure the effect of JNJ-42226314 on extracellular concentrations of norepinephrine in the medial prefrontal cortex of freely moving rats. Both 3 and $30 \mathrm{mg} / \mathrm{kg}$ (i.p.) evoked time- and dose-dependent increases in cortical norepinephrine, with concentrations peaking at approximately $175 \%(3 \mathrm{mg} / \mathrm{kg})$ and $250 \%(30 \mathrm{mg} / \mathrm{kg})$ of baseline measurements (vehicle baseline: $0.167 \pm 0.007 \mathrm{pg} / \mu \mathrm{l} ; 3 \mathrm{mg} / \mathrm{kg}$ baseline: $0.196 \pm$ $0.011 \mathrm{pg} / \mu \mathrm{l} ; 30 \mathrm{mg} / \mathrm{kg}$ baseline: $0.188 \pm 0.011 \mathrm{pg} / \mu \mathrm{l}) 60$ minutes after compound administration (Fig. 7A). Norepinephrine levels in animals treated with $30 \mathrm{mg} / \mathrm{kg}$ remained elevated versus vehicle-treated animals for the duration of the 150minute postdose collection period $(P<0.001)$, whereas they returned to baseline levels after 60 minutes in animals treated with $3 \mathrm{mg} / \mathrm{kg}$. AUC analysis for the 150 -minute postdosing collection period revealed significant treatment effects of JNJ-42226314 on NE levels $\left[\mathrm{F}_{(2,22)}=103.5, P<0.0001\right]$ (Fig. 7B).

JNJ-42226314 Is Antinociceptive in the Rat CFA Model of Inflammatory Pain. In the CFA model of inflammatory pain, $30 \mathrm{mg} / \mathrm{kg} \mathrm{JNJ}-42226314$ produced a complete time-dependent reversal of hypersensitivity to a radiant heat stimulus, with a statistically significant effect versus vehicle treatment observed from 30 to 180 minutes post-compound administration and the peak effect occurring at 100 minutes (Fig. 8A). In separate groups of animals, the antihyperalgesic effect of JNJ-42226314 at 100 minutes post-compound administration was shown to be dose-dependent (Fig. 8B), with an $\mathrm{ED}_{50}$ value of $3.0 \mathrm{mg} / \mathrm{kg}$ (PharmTools Pro). In addition, JNJ-42226314 reversed mechanical hypersensitivity in the paw pressure test (unpublished data).

In the same animals used for the CFA experiment, blood samples and brains were removed from the rats immediately following the last behavioral measure and analyzed for JNJ42226314 concentration as well as 2-AG. At the calculated $\mathrm{ED}_{50}$ value of $3.0 \mathrm{mg} / \mathrm{kg}$, levels of JNJ-42226314 in plasma and brain were $66 \mathrm{ng} / \mathrm{ml}$ and $166 \mathrm{ng} / \mathrm{g}$, respectively, and the levels of $2-\mathrm{AG}$ were $170 \mathrm{ng} / \mathrm{ml}$ and $12,522 \mathrm{ng} / \mathrm{g}$, respectively.

JNJ-42226314 Is Antinociceptive the Rat CCI Model of Neuropathic Pain. In the CCI model of neuropathic pain, $10 \mathrm{mg} / \mathrm{kg}$ JNJ-42226314 almost completely inhibited acetoneinduced flinching responses in CCI-treated rats in a timedependent manner, with the peak effect occurring at 1 hour. Statistically significant inhibition versus vehicle treatment 


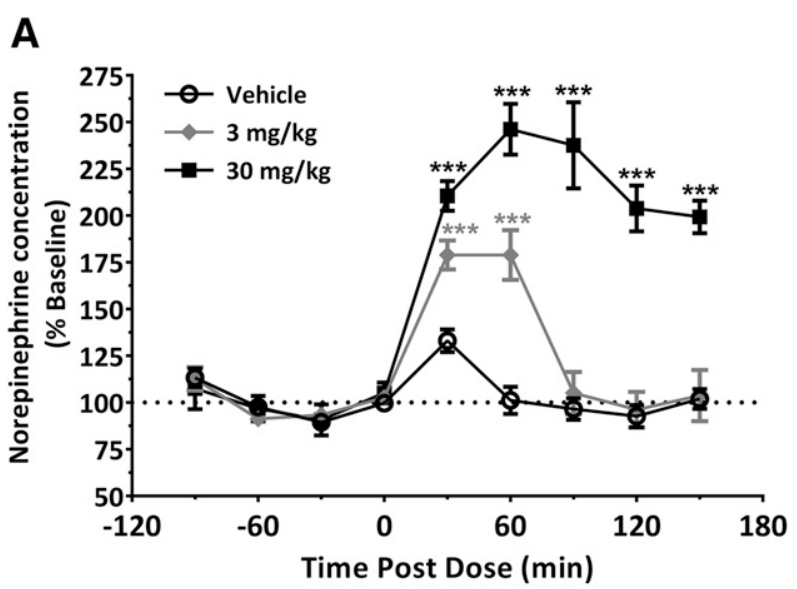

B

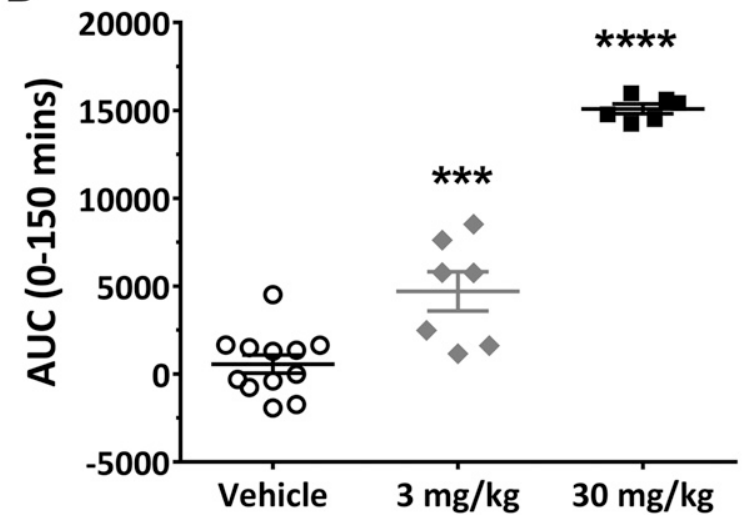

Fig. 7. JNJ-42226314 induced elevation of cortical norepinephrine levels. (A) Effects of vehicle $(N=12), 3 \mathrm{mg} / \mathrm{kg}(N=7)$, or $30 \mathrm{mg} / \mathrm{kg}(N=6)$ i.p. JNJ42226314 on extracellular norepinephrine levels from rat medial prefrontal cortex in vivo. Values are normalized to average predosing (baseline) levels for each animal. Dosing at $\mathrm{t}=0$ minutes. (B) Total AUC for the 150-minute period following vehicle or compound administration. Each symbol represents AUC value from an individual animal. Lines indicate mean \pm S.E.M. (A and B): $* * * P<0.001 ; * * * * P<0.0001$ vs. vehicle.

was observed at 1- and 3-hour post-compound administration (Fig. 8C). In separate groups of animals, the anticold allodynic effect of JNJ-42226314 at 1-hour post-compound administration was shown to be dose-dependent, with an $\mathrm{ED}_{50}$ value of $1.42 \mathrm{mg} / \mathrm{kg}$ (Fig. 8D).

\section{Discussion}

Reported here is the in vitro and in vivo pharmacologic characterization of the reversible, competitive, and selective MAGL inhibitor JNJ-42226314. In vitro binding studies demonstrated selectivity of JNJ-42226314 for MAGL over other serine hydrolases and potential targets, including CB1 and CB2, whereas in vivo studies indicate time- and dosedependent engagement of MAGL and, indirectly, CB1 via elevated 2-AG levels. These studies also confirm that partial inhibition of MAGL is sufficient to elevate brain 2-AG, with the maximal increase being approximately 10 -fold in rat and nearly 20 -fold in mouse after administration of $30 \mathrm{mg} / \mathrm{kg}$ JNJ-42226314. Increased CB1 engagement by elevated 2-AG levels is also supported by the hypothermia observed in $30 \mathrm{mg} / \mathrm{kg}$-treated rats-an effect consistent with what is seen in response to direct CB1 agonists (Wiley et al., 1998).
Augmenting endocannabinoid signaling by limiting enzymatic degradation has emerged as a compelling therapeutic strategy (Mulvihill and Nomura, 2013; Clapper et al., 2018). Several irreversible MAGL inhibitors, including JZL-184, MJN110, and SAR-127303, have been used as tool compounds to validate preclinical pharmacology associated with MAGL inhibition. One such inhibitor, 1,1,1,3,3,3-hexafluoropropan2-yl 4-[[2-pyrrolidin-1-yl-4-(trifluoromethyl)phenyl]methyl]piperazine-1-carboxylate (ABX-1431), is currently undergoing clinical evaluation (Cisar et al., 2018). All of these inhibitors bind covalently to the catalytic Ser122 residue of MAGL (Bertrand et al., 2010; Griebel et al., 2015; McAllister et al., 2018). Because of their inherent electrophilicity, however, idiosyncratic immune-mediated drug toxicity is a significant pharmaceutic risk of covalent inhibitors, especially in treatment of chronic diseases (Johnson et al., 2010). Recently, several noncovalent MAGL inhibitors have been described (Tuccinardi et al., 2014; Aghazadeh Tabrizi et al., 2018; Aida et al., 2018; Granchi et al., 2019), potentially providing a means of reducing such risks.

Potential consequences of CB1 activation in the CNS include impaired memory and cognition, which are associated with alterations in the underlying synaptic properties that subserve these functions (Hill et al., 2004). For example, direct CB1 agonists, when administered at doses that induce hippocampal synaptic depression in vivo, also impair spatial working memory (Han et al., 2012). In this study, the effects of JNJ-42226314 on hippocampal synaptic potentials were examined, given the well-defined role of the hippocampus in learning and memory and the high levels of MAGL and CB1 expression there (Herkenham et al., 1991). In addition, higher order network oscillations associated with conscious perception and attention are similarly disrupted with CB1 agonists in animal models (Hájos et al., 2000; Hajós et al., 2008; SalesCarbonell et al., 2013) as well as in humans (Skosnik et al., 2006; Cortes-Briones et al., 2015). Thus, the effects of JNJ42226314 on EEG gamma power, a measure associated with attention, memory, and perception across species (Pesaran et al., 2002; Bauer et al., 2007; Fries et al., 2007) were also examined. Three milligram per kilogram JNJ-42226314 did not significantly affect either hippocampal synaptic transmission or gamma power; however, $30 \mathrm{mg} / \mathrm{kg}$ significantly reduced both measures. These dose-dependent effects are consistent with those observed with the MAGL inhibitor JZL-184, which has been shown to elicit dose-dependent depression of hippocampal synaptic activity in mice (Wang et al., 2017) as well as of wake gamma power (Pava et al., 2016).

Though the effects of CB1 agonists on learning, memory, and cognition are well-studied, the impact of MAGL inhibition on these functions is less clear. Whereas memory impairments in rodents have been reported with SAR-127303 (Griebel et al., 2015), low doses of JZL-184 have led to either improved performance (Xu et al., 2014) or no effect (Busquets-Garcia et al., 2011) in various associative learning tasks. These discrepant outcomes could reflect the different learning and memory paradigms employed and/or differences in the relative degrees of 2-AG elevation induced by the different MAGL inhibitors and doses administered. Here, $3 \mathrm{mg} / \mathrm{kg} \mathrm{JNJ}-$ 42226314 elevated hippocampal and whole-brain 2-AG approximately 3-fold while not significantly altering either measure of CNS function (hippocampal synaptic transmission or gamma 

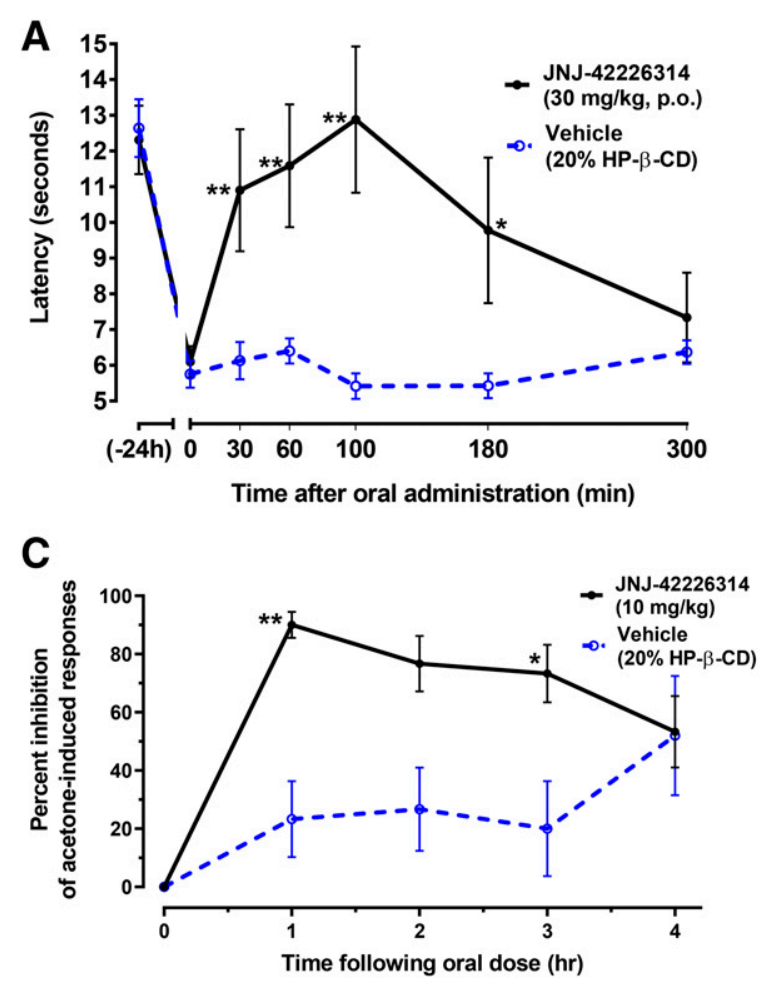

B

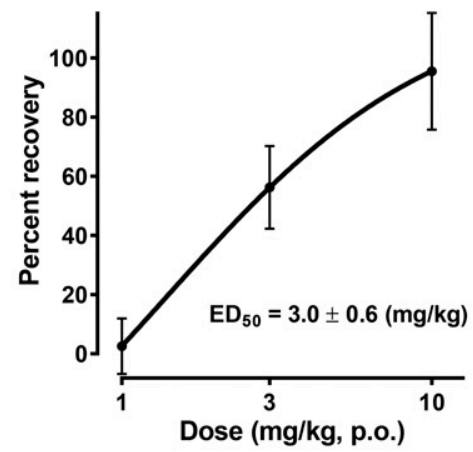

D

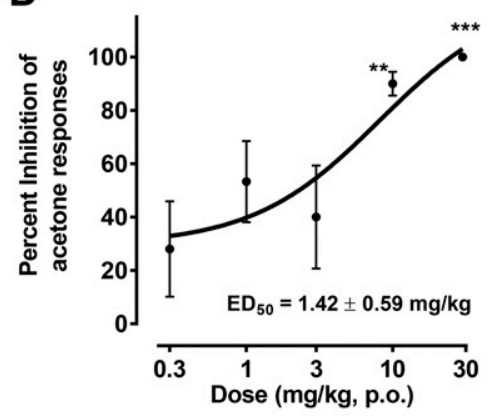

Fig. 8. Antinociceptive effects of JNJ42226314 in models of inflammatory and neuropathic pain. (A) Time course for JNJ-42226314 in the rat CFA radiant heat test. JNJ-42226314 was evaluated at an oral dose of $30 \mathrm{mg} / \mathrm{kg}$ in the CFA radiant heat test. Shown are the mean \pm S.E.M. of the withdrawal latencies for vehicle- and compound-treated rats $(N=$ 8 per group; $* P<0.05$, $* * P<0.01)$. (B) Dose-response relationship for JNJ42226314 reversal of CFA-induced thermal hyperalgesia in the rat. Shown are the mean \pm S.E.M. of the withdrawal latencies at the stated doses 100 minutes after drug administration $(N=8$ per group). (C) Time course of JNJ-42226314 inhibition of cold allodynia in chronic CCI-treated rats. Shown are the mean \pm S.E.M. of the percent inhibition of the acetone-induced responses following the administration of vehicle or JNJ-42226314 (10 mg/kg, per os.) $(N=6$ per group; $* P<$ 0.05 , $* * P<0.01$ ). (D) Dose-response relationship of JNJ-42226314 inhibition of cold allodynia in CCI-treated rats. Shown are the mean \pm S.E.M. of the percent inhibition of acetone-induced responses at the stated doses of JNJ-42226314 1 hour following its administration $(N=6$ per group; $* * P<0.01$, *** $P<0.001)$. power), suggesting a potential degree of MAGL inhibition that would not adversely affect memory or cognition.

Endocannabinoids also play a significant role in the regulation of sleep stability. In general, increased endocannabinoid activity is often, but not always, associated with sleeppromoting or stabilizing effects (Prospéro-García et al., 2016). JZL-184, for example, dose-dependently increases NREM sleep duration in mice while also decreasing REM duration (Pava et al., 2016). These results are partially at odds with those observed in the present study, wherein JNJ-42226134 had an overall dose-dependent, wake-promoting effect by reducing both NREM and REM sleep in rats. Notably, JNJ-42226314 was administered just after light-phase onset, when the animals are normally inactive. Circulating endocannabinoids demonstrate circadian fluctuations, with high levels of 2-AG in the light phase and low levels in the dark phase in both humans and rodents (Valenti et al., 2004; Hanlon et al., 2015). Thus, time of day is an important factor in assessing the effects of MAGL inhibition on sleep. Supporting this, while NREM sleep was initially elevated when JZL-184 was administered at darkphase onset, a biphasic effect was observed, wherein NREM was subsequently reduced after light-phase onset (Pava et al., 2016). Whether a similar NREM increase would be observed were JNJ-42226314 to be administered around dark-phase onset will require further study. With respect to sleep, no other MAGL inhibitor has been tested in rats, and species differences may account for the discrepancy of these sleep effects. Notably, baseline levels of 2-AG are substantially lower in mice than in rats, which could potentially affect the sleep response. The observed dose-dependent suppression by JNJ-42226314 on REM sleep, however, is consistent with that reported in mice with JZL-184 in the Pava et al. (2016) study, in which high doses of the MAGL inhibitor also nearly abolished REM sleep in the light phase for several hours after dosing. Interestingly, a similar effect on REM was also reported upon dosing with the CB1 antagonist 1-(2,4-dichlorophenyl)-5-(4-iodophenyl)4-methyl- $N$-4-morpholinyl-1H-pyrazole-3-carboxamide (AM-281), suggesting an overall sensitivity to endocannabinoid manipulations. Collectively, the effects on sleep and wake states reported here raise a number of interesting questions regarding potential biphasic, circadian effects of MAGL inhibition with JNJ-42226314, which would be the subject of future study.

The increased wakefulness induced by JNJ-42226314 is likely driven, at least in part, by the observed elevations in cortical norepinephrine release. Norepinephrine has a wellestablished role in maintaining general arousal, and noradrenergic neurons project to many arousal-regulating brain regions, including the cortex (Berridge and Waterhouse, 2003; Mitchell and Weinshenker, 2010; Watson et al., 2010). These neurons are highly active during wakefulness, moderately active during NREM sleep, and nearly silent during REM sleep (Aston-Jones and Bloom, 1981). Cannabinoid administration has been reported to increase norepinephrine release in the prefrontal cortex (Oropeza et al., 2007; Page et al., 2007, 2008) as well as increase c-fos expression in noradrenergic neurons and modulate their firing rate [reviewed in Carvalho and Van Bockstaele (2012)]. How endocannabinoid signaling modulates noradrenergic activity has yet to be conclusively determined, but there is evidence to indicate that this is accomplished via a suppression of GABAergic inhibitory inputs onto noradrenergic neurons (Scavone et al., 2010).

Elevating endocannabinoids, either pharmacologically or genetically, was shown to have antinociceptive effects in many rodent models of inflammatory and neuropathic pain [reviewed in Woodhams et al. (2017)]. Exogenous CB agonists can also produce similar effects (Bridges et al., 2001). Consistent with these observations, acute administration of JNJ-42226314 dose-dependently reduced nociceptive behavior in both the CFA model of inflammatory pain and in the CCI model of neuropathic pain. However, complete and prolonged MAGL 
inhibition, or MAGL genetic deletion, may also induce CB1 desensitization and down-regulation, which in turn may lead to tolerance to the antinociceptive effects of MAGL inhibitors (Chanda et al., 2010; Schlosburg et al., 2010; Kinsey et al., 2013; Ignatowska-Jankowska et al., 2014). It is unclear whether efficacious doses of JNJ-42226314, when sustained over time, would lead to a similar CB1 desensitization and subsequent antinociceptive tolerance. One important factor is that these prior studies were performed with covalent MAGL inhibitors, such as JZL-184 and KML-29. It remains to be determined whether these effects would be as pronounced with a reversible inhibitor like JNJ-42226314 given that MAGL occupancy returns to near zero levels 24 hours after administration, even at relatively high doses.

In conclusion, we report the mechanistic and pharmacologic characterization of JNJ-42226314, a novel potent and reversible MAGL inhibitor with high target selectivity and in vivo efficacy. JNJ-42226314 dose-dependently increased 2 -AG in vivo and displayed antinociceptive properties at doses that do not impact measures of CNS function associated with memory and cognition. Dose-dependent effects toward increased wakefulness were observed, which will need to be investigated further and in more detail. With regards to clinical implications, the reversible mode of action presents a relatively unexplored but potentially beneficial mechanism that could allow for better temporal control over circadian 2AG fluctuations, reduced CB1 desensitization, and improved safety in humans versus covalent MAGL inhibitors, especially for treatment of chronic diseases.

\section{Acknowledgments}

We gratefully acknowledge the assistance of Dr. Kevin Sharp and his staff at Janssen Research \& Development LLC (San Diego, CA). The authors also thank Bruce Grasberger and Heather Murrey for the recombinant human MAGL generation and assistance in the ABPP experiments, respectively, and Ondrej Libiger for statistical consultation.

\section{Authorship Contributions}

Participated in research design: Wyatt, Fraser, Welty, Lord, Wennerholm, Sutton, Ameriks, Dugovic, Yun, Koudriakova, Tian, Szewczuk, Ahn, Flores, Connolly, Macielag, Brandt, Zhang, Lovenberg, Bonaventure.

Conducted experiments: Wyatt, Fraser, Welty, Lord, Wennerholm, Sutton, Yun, White, Tian, Suarez, Szewczuk, Bonnette, Zhu, Chevalier, Zhang.

Contributed new reagents or analytic tools: Ameriks, Nguyen, Ahn, Ghosh, Flores, Macielag.

Performed data analysis: Wyatt, Fraser, Welty, Lord, Wennerholm, Sutton, Dugovic, Yun, White, Nguyen, Tian, Suarez, Szewczuk, Bonnette, Chevalier, Zhang.

Wrote or contributed to the writing of the manuscript: Wyatt, Fraser, Lord, Wennerholm, Sutton, Ameriks, Dugovic, Nguyen, Tian, Szewczuk, Ahn, Flores, Bonaventure.

\section{References}

Aghazadeh Tabrizi M, Baraldi PG, Baraldi S, Ruggiero E, De Stefano L, Rizzolio F, Di Cesare Mannelli L, Ghelardini C, Chicca A, Lapillo M, et al. (2018) Discovery of 1,5-diphenylpyrazole-3-carboxamide derivatives as potent, reversible, and selective monoacylglycerol lipase (MAGL) inhibitors. J Med Chem 61:1340-1354.

Ahn K, Johnson DS, Mileni M, Beidler D, Long JZ, McKinney MK, Weerapana E Sadagopan N, Liimatta M, Smith SE, et al. (2009) Discovery and characterization of a highly selective FAAH inhibitor that reduces inflammatory pain. Chem Biol 16:411-420.

Aida J, Fushimi M, Kusumoto T, Sugiyama H, Arimura N, Ikeda S, Sasaki M, Sogabe S, Aoyama K, and Koike T (2018) Design, synthesis, and evaluation of piperaziny pyrrolidin-2-ones as a novel series of reversible monoacylglycerol lipase inhibitors. J Med Chem 61:9205-9217.
Aston-Jones G and Bloom FE (1981) Activity of norepinephrine-containing locus coeruleus neurons in behaving rats anticipates fluctuations in the sleep-waking cycle. J Neurosci 1:876-886.

Basavarajappa BS (2007) Neuropharmacology of the endocannabinoid signaling system-molecular mechanisms, biological actions and synaptic plasticity. Curr Neuropharmacol 5:81-97.

Bauer EP, Paz R, and Paré D (2007) Gamma oscillations coordinate amygdalo-rhinal interactions during learning. $J$ Neurosci 27:9369-9379.

Bedse G, Bluett RJ, Patrick TA, Romness NK, Gaulden AD, Kingsley PJ, Plath N, Marnett LJ, and Patel S (2018) Therapeutic endocannabinoid augmentation for mood and anxiety disorders: comparative profiling of FAAH, MAGL and dual inhibitors. Transl Psychiatry 8:92.

Bedse G, Hartley ND, Neale E, Gaulden AD, Patrick TA, Kingsley PJ, Uddin MJ, Plath N, Marnett LJ, and Patel S (2017) Functional redundancy between canonical endocannabinoid signaling systems in the modulation of anxiety. Biol Psychiatry 82:488-499.

Bennett GJ and Xie YK (1988) A peripheral mononeuropathy in rat that produces disorders of pain sensation like those seen in man. Pain 33:87-107.

Bernal-Chico A, Canedo M, Manterola A, Victoria Sánchez-Gómez M, Pérez-Samartín A, Rodríguez-Puertas R, Matute C, and Mato S (2015) Blockade of monoacylglycerol lipase inhibits oligodendrocyte excitotoxicity and prevents demyelination in vivo. Glia 63:163-176.

Berridge CW and Waterhouse BD (2003) The locus coeruleus-noradrenergic system: modulation of behavioral state and state-dependent cognitive processes. Brain Res Brain Res Rev 42:33-84.

Bertrand T, Augé F, Houtmann J, Rak A, Vallée F, Mikol V, Berne PF, Michot N, Cheuret D, Hoornaert C, et al. (2010) Structural basis for human monoglyceride lipase inhibition. J Mol Biol 396:663-673.

Bridges D, Ahmad K, and Rice AS (2001) The synthetic cannabinoid WIN55,212-2 attenuates hyperalgesia and allodynia in a rat model of neuropathic pain. $\mathrm{Br}$ $J$ Pharmacol 133:586-594.

Buczynski MW and Parsons LH (2010) Quantification of brain endocannabinoid levels: methods, interpretations and pitfalls. $\mathrm{Br}$ J Pharmacol 160:423-442.

Busquets-Garcia A, Puighermanal E, Pastor A, de la Torre R, Maldonado R, and Ozaita A (2011) Differential role of anandamide and 2-arachidonoylglycerol in memory and anxiety-like responses. Biol Psychiatry 70:479-486.

Carvalho AF and Van Bockstaele EJ (2012) Cannabinoid modulation of noradrenergic circuits: implications for psychiatric disorders. Prog Neuropsychopharmacol Biol Psychiatry 38:59-67.

Chanda PK, Gao Y, Mark L, Btesh J, Strassle BW, Lu P, Piesla MJ, Zhang MY, Bingham B, Uveges A, et al. (2010) Monoacylglycerol lipase activity is a critical modulator of the tone and integrity of the endocannabinoid system. Mol Pharmacol 78:996-1003.

Chang JW, Niphakis MJ, Lum KM, Cognetta AB III, Wang C, Matthews ML, Niessen S, Buczynski MW, Parsons LH, and Cravatt BF (2012) Highly selective inhibitors of monoacylglycerol lipase bearing a reactive group that is bioisosteric with endocannabinoid substrates. Chem Biol 19:579-588.

Chen R, Zhang J, Wu Y, Wang D, Feng G, Tang YP, Teng Z, and Chen C (2012) Monoacylglycerol lipase is a therapeutic target for Alzheimer's disease. Cell Rep 2:1329-1339.

Cheng Y and Prusoff WH (1973) Relationship between the inhibition constant (K1) and the concentration of inhibitor which causes 50 per cent inhibition (I50) of an enzymatic reaction. Biochem Pharmacol 22:3099-3108.

Christensen R, Kristensen PK, Bartels EM, Bliddal H, and Astrup A (2007) Efficacy and safety of the weight-loss drug rimonabant: a meta-analysis of randomised trials. Lancet 370:1706-1713.

Cisar JS, Weber OD, Clapper JR, Blankman JL, Henry CL, Simon GM, Alexander JP, Jones TK, Ezekowitz RAB, O’Neill GP, et al. (2018) Identification of ABX-1431, a selective inhibitor of monoacylglycerol lipase and clinical candidate for treatment of neurological disorders. J Med Chem 61:9062-9084.

Clapper JR, Henry CL, Niphakis MJ, Knize AM, Coppola AR, Simon GM, Ngo N, Herbst RA, Herbst DM, Reed AW, et al. (2018) Monoacylglycerol lipase inhibition in human and rodent systems supports clinical evaluation of endocannabinoid modulators. J Pharmacol Exp Ther 367:494-508.

Copeland RA (2005) Evaluation of enzyme inhibitors in drug discovery. A guide for medicinal chemists and pharmacologists. Methods Biochem Anal 46:1-265.

Cortes-Briones J, Skosnik PD, Mathalon D, Cahill J, Pittman B, Williams A, Sewell RA, Ranganathan M, Roach B, Ford J, et al. (2015) $\Delta 9$-THC disrupts gamma $(\gamma)$-band neural oscillations in humans. Neuropsychopharmacology 40:2124-2134. Dinh TP, Kathuria S, and Piomelli D (2004) RNA interference suggests a primary role for monoacylglycerol lipase in the degradation of the endocannabinoid 2arachidonoylglycerol. Mol Pharmacol 66:1260-1264.

Fries P, Nikolić D, and Singer W (2007) The gamma cycle. Trends Neurosci 30: 309-316.

Funk CD (2001) Prostaglandins and leukotrienes: advances in eicosanoid biology. Science 294:1871-1875.

Gatley SJ, Gifford AN, Volkow ND, Lan R, and Makriyannis A (1996) 123I-labeled AM251: a radioiodinated ligand which binds in vivo to mouse brain cannabinoid CB1 receptors. Eur J Pharmacol 307:331-338.

Ghosh S, Wise LE, Chen Y, Gujjar R, Mahadevan A, Cravatt BF, and Lichtman AH (2013) The monoacylglycerol lipase inhibitor JZL184 suppresses inflammatory pain in the mouse carrageenan model. Life Sci 92:498-505.

Granchi C, Lapillo M, Glasmacher S, Bononi G, Licari C, Poli G, El Boustani M Caligiuri I, Rizzolio F, Gertsch J, et al. (2019) Optimization of a benzoylpiperidine class identifies a highly potent and selective reversible monoacylglycerol lipase (MAGL) inhibitor. J Med Chem 62:1932-1958.

Griebel G, Pichat P, Beeské S, Leroy T, Redon N, Jacquet A, Francon D, Bert L, Even L, Lopez-Grancha M, et al. (2015) Selective blockade of the hydrolysis of the endocannabinoid 2-arachidonoylglycerol impairs learning and memory performance while producing antinociceptive activity in rodents. Sci Rep 5:7642.

Hajós M, Hoffmann WE, and Kocsis B (2008) Activation of cannabinoid-1 receptors disrupts sensory gating and neuronal oscillation: relevance to schizophrenia. Biol Psychiatry 63:1075-1083. 
Hájos N, Katona I, Naiem SS, MacKie K, Ledent C, Mody I, and Freund TF (2000) Cannabinoids inhibit hippocampal GABAergic transmission and network oscillations. Eur J Neurosci 12:3239-3249.

Han J, Kesner P, Metna-Laurent M, Duan T, Xu L, Georges F, Koehl M, Abrous DN, Mendizabal-Zubiaga J, Grandes P, et al. (2012) Acute cannabinoids impair working memory through astroglial CB1 receptor modulation of hippocampal LTD. Cell 148:1039-1050.

Hanlon EC, Tasali E, Leproult R, Stuhr KL, Doncheck E, de Wit H, Hillard CJ, and Van Cauter E (2015) Circadian rhythm of circulating levels of the endocannabinoid 2-arachidonoylglycerol. J Clin Endocrinol Metab 100:220-226.

Herkenham M, Lynn AB, Johnson MR, Melvin LS, de Costa BR, and Rice KC (1991) Characterization and localization of cannabinoid receptors in rat brain: a quantitative in vitro autoradiographic study. J Neurosci 11:563-583.

Herkenham M, Lynn AB, Little MD, Johnson MR, Melvin LS, de Costa BR, and Rice KC (1990) Cannabinoid receptor localization in brain. Proc Natl Acad Sci USA 87: 1932-1936.

Hernández-Torres G, Cipriano M, Hedén E, Björklund E, Canales Á, Zian D, Feliú A, Mecha M, Guaza C, Fowler CJ, et al. (2014) A reversible and selective inhibitor of monoacylglycerol lipase ameliorates multiple sclerosis. Angew Chem Int Ed Engl 53:13765-13770.

Hill MN, Bierer LM, Makotkine I, Golier JA, Galea S, McEwen BS, Hillard CJ, and Yehuda $\mathrm{R}$ (2013) Reductions in circulating endocannabinoid levels in individuals with post-traumatic stress disorder following exposure to the World Trade Center attacks. Psychoneuroendocrinology 38:2952-2961.

Hill MN, Froc D.J, Fox CJ, Gorzalka BB, and Christie BR (2004) Prolonged cannabinoid treatment results in spatial working memory deficits and impaired long-term potentiation in the CA1 region of the hippocampus in vivo. Eur $J$ Neurosci 20:859-863.

Hill MN and Gorzalka BB (2009) The endocannabinoid system and the treatment of mood and anxiety disorders. CNS Neurol Disord Drug Targets 8:451-458.

Hill MN, Miller GE, Carrier EJ, Gorzalka BB, and Hillard CJ (2009) Circulating endocannabinoids and $\mathrm{N}$-acyl ethanolamines are differentially regulated in major depression and following exposure to social stress. Psychoneuroendocrinology 34:1257-1262.

Hill MN, Miller GE, Ho WS, Gorzalka BB, and Hillard CJ (2008) Serum endocannabinoid content is altered in females with depressive disorders: a preliminary report. Pharmacopsychiatry 41:48-53.

Ignatowska-Jankowska BM, Ghosh S, Crowe MS, Kinsey SG, Niphakis MJ, Abdullah RA, Tao Q, O' Neal ST, Walentiny DM, Wiley JL, et al. (2014) In vivo characterization of the highly selective monoacylglycerol lipase inhibitor KML29: antinociceptive activity without cannabimimetic side effects. Br J Pharmacol 171:1392-1407.

Jessani N, Liu Y, Humphrey M, and Cravatt BF (2002) Enzyme activity profiles of the secreted and membrane proteome that depict cancer cell invasiveness. Proc Natl Acad Sci USA 99:10335-10340.

Johnson DS, Weerapana E, and Cravatt BF (2010) Strategies for discovering and derisking covalent, irreversible enzyme inhibitors. Future Med Chem 2:949-964.

Katz PS, Sulzer JK, Impastato RA, Teng SX, Rogers EK, and Molina PE (2015) Endocannabinoid degradation inhibition improves neurobehavioral function, blood-brain barrier integrity, and neuroinflammation following mild traumatic brain injury. $J$ Neurotrauma 32:297-306.

Kidd D, Liu Y, and Cravatt BF (2001) Profiling serine hydrolase activities in complex proteomes. Biochemistry 40:4005-4015.

Kinsey SG, Wise LE, Ramesh D, Abdullah R, Selley DE, Cravatt BF, and Lichtman AH (2013) Repeated low-dose administration of the monoacylglycerol lipase in hibitor JZL184 retains cannabinoid receptor type 1-mediated antinociceptive and gastroprotective effects. J Pharmacol Exp Ther 345:492-501.

Labar G, Bauvois C, Muccioli GG, Wouters J, and Lambert DM (2007) Disulfiram is an inhibitor of human purified monoacylglycerol lipase, the enzyme regulating 2arachidonoylglycerol signaling. ChemBioChem 8:1293-1297.

Leung D, Hardouin C, Boger DL, and Cravatt BF (2003) Discovering potent and selective reversible inhibitors of enzymes in complex proteomes. Nat Biotechnol 21:687-691

Liu Y, Patricelli MP, and Cravatt BF (1999) Activity-based protein profiling: the serine hydrolases. Proc Natl Acad Sci USA 96:14694-14699.

Long JZ and Cravatt BF (2011) The metabolic serine hydrolases and their function in mammalian physiology and disease. Chem Rev 111:6022-6063.

Long JZ, Li W, Booker L, Burston JJ, Kinsey SG, Schlosburg JE, Pavón FJ, Serrano AM, Selley DE, Parsons LH, et al. (2009a) Selective blockade of 2 arachidonoylglycerol hydrolysis produces cannabinoid behavioral effects. Nat Chem Biol 5:37-44

Long JZ, Nomura DK, Vann RE, Walentiny DM, Booker L, Jin X, Burston JJ, SimSelley LJ, Lichtman AH, Wiley JL, et al. (2009b) Dual blockade of FAAH and MAGL identifies behavioral processes regulated by endocannabinoid crosstalk in vivo. Proc Natl Acad Sci USA 106:20270-20275.

McAllister LA, Butler CR, Mente S, O’Neil SV, Fonseca KR, Piro JR, Cianfrogna JA Foley TL, Gilbert AM, Harris AR, et al. (2018) Discovery of trifluoromethyl glycol carbamates as potent and selective covalent monoacylglycerol lipase (MAGL) inhibitors for treatment of neuroinflammation. J Med Chem 61:3008-3026.

Mitchell HA and Weinshenker D (2010) Good night and good luck: norepinephrine in sleep pharmacology. Biochem Pharmacol 79:801-809.

Mulvihill MM and Nomura DK (2013) Therapeutic potential of monoacylglycerol lipase inhibitors. Life Sci 92:492-497.

National Research Council (2011) Guide for the Care and Use of Laboratory Animals: Eighth Edition. Washington, DC: The National Academies Press.

Nomanbhoy TK, Rosenblum J, Aban A, and Burbaum JJ (2003) Inhibitor focusing: direct selection of drug targets from proteomes using activity-based probes. Assay Drug Dev Technol 1:137-146.

Nomura DK, Morrison BE, Blankman JL, Long JZ, Kinsey SG, Marcondes MC, Ward AM, Hahn YK, Lichtman AH, Conti B, et al. (2011) Endocannabinoid hydrolysis generates brain prostaglandins that promote neuroinflammation. Science 334:809-813.

Oropeza VC, Mackie K, and Van Bockstaele EJ (2007) Cannabinoid receptors are localized to noradrenergic axon terminals in the rat frontal cortex. Brain Res 1127: $36-44$.
Page ME, Oropeza VC, Sparks SE, Qian Y, Menko AS, and Van Bockstaele EJ (2007) Repeated cannabinoid administration increases indices of noradrenergic activity in rats. Pharmacol Biochem Behav 86:162-168.

Page ME, Oropeza VC, and Van Bockstaele EJ (2008) Local administration of a cannabinoid agonist alters norepinephrine efflux in the rat frontal cortex. Neurosci Lett 431:1-5.

Pan B, Wang W, Long JZ, Sun D, Hillard C.J, Cravatt BF, and Liu QS (2009) Blockade of 2-arachidonoylglycerol hydrolysis by selective monoacylglycerol lipase inhibitor 4-nitrophenyl 4-(dibenzo[d][1,3]dioxol-5-yl(hydroxy)methyl)piperidine-1carboxylate (JZL184) enhances retrograde endocannabinoid signaling. $J$ Pharmacol Exp Ther 331:591-597.

Parsons WH, Calvo RR, Cheung W, Lee YK, Patel S, Liu J, Youngman MA, Dax SL Stone D, Qin N, et al. (2015) Benzo[d]imidazole transient receptor potential vanilloid 1 antagonists for the treatment of pain: discovery of trans-2-(2-\{2-[2-(4Trifluoromethyl-phenyl)-vinyl]-1H-benzimidazol-5-yl\}-phenyl)-propan-2-ol (mavatrep). J Med Chem 58:3859-3874.

Patel S, Hill MN, Cheer JF, Wotjak CT, and Holmes A (2017) The endocannabinoid system as a target for novel anxiolytic drugs. Neurosci Biobehav Rev 76 (Pt A): $56-66$

Patricelli MP, Giang DK, Stamp LM, and Burbaum JJ (2001) Direct visualization of serine hydrolase activities in complex proteomes using fluorescent active sitedirected probes. Proteomics 1:1067-1071.

Pava MJ, Makriyannis A, and Lovinger DM (2016) Endocannabinoid signaling regulates sleep stability. PLoS One 11:e0152473.

Pesaran B, Pezaris JS, Sahani M, Mitra PP, and Andersen RA (2002) Temporal structure in neuronal activity during working memory in macaque parietal cortex. Nat Neurosci 5:805-811.

Prospéro-García O, Amancio-Belmont O, Becerril Meléndez AL, Ruiz-Contreras AE, and Méndez-Díaz M (2016) Endocannabinoids and sleep. Neurosci Biobehav Rev 71:671-679.

Robson PJ (2014) Therapeutic potential of cannabinoid medicines. Drug Test Anal 6: 24-30.

Sales-Carbonell C, Rueda-Orozco PE, Soria-Gómez E, Buzsáki G, Marsicano G, and Robbe D (2013) Striatal GABAergic and cortical glutamatergic neurons mediate contrasting effects of cannabinoids on cortical network synchrony. Proc Natl Acad Sci USA 110:719-724.

Scavone JL, Mackie K, and Van Bockstaele EJ (2010) Characterization of cannabinoid-1 receptors in the locus coeruleus: relationship with mu-opioid receptors. Brain Res 1312:18-31.

Schalk-Hihi C, Schubert C, Alexander R, Bayoumy S, Clemente JC, Deckman I, DesJarlais RL, Dzordzorme KC, Flores CM, Grasberger B, et al. (2011) Crystal structure of a soluble form of human monoglyceride lipase in complex with an inhibitor at 1.35 A resolution. Protein Sci 20:670-683.

Schlosburg JE, Blankman JL, Long JZ, Nomura DK, Pan B, Kinsey SG, Nguyen PT, Ramesh D, Booker L, Burston JJ, et al. (2010) Chronic monoacylglycerol lipase blockade causes functional antagonism of the endocannabinoid system. Nat Neurosci 13:1113-1119.

Skosnik PD, Krishnan GP, Aydt EE, Kuhlenshmidt HA, and O’Donnell BF (2006) Psychophysiological evidence of altered neural synchronization in cannabis use: relationship to schizotypy. Am J Psychiatry 163:1798-1805.

Tuccinardi T, Granchi C, Rizzolio F, Caligiuri I, Battistello V, Toffoli G, Minutolo F, Macchia M, and Martinelli A (2014) Identification and characterization of a new reversible MAGL inhibitor. Bioorg Med Chem 22:3285-3291.

Tuo W, Leleu-Chavain N, Spencer J, Sansook S, Millet R, and Chavatte P (2017) Therapeutic potential of fatty acid amide hydrolase, monoacylglycerol lipase, and $\mathrm{N}$-acylethanolamine acid amidase inhibitors. J Med Chem 60:4-46.

Valenti M, Viganò D, Casico MG, Rubino T, Steardo L, Parolaro D, and Di Marzo V (2004) Differential diurnal variations of anandamide and 2-arachidonoyl-glycerol levels in rat brain. Cell Mol Life Sci 61:945-950.

von Rüden EL, Bogdanovic RM, Wotjak CT, and Potschka H (2015) Inhibition of monoacylolycerol lipase mediates a cannabinoid 1-receptor dependent delay of kindling progression in mice. Neurobiol Dis 77:238-245.

Wang Y, Gu N, Duan T, Kesner P, Blaskovits F, Liu J, Lu Y, Tong L, Gao F, Harris C, et al. (2017) Monoacylglycerol lipase inhibitors produce pro- or antidepressant responses via hippocampal CA1 GABAergic synapses. Mol Psychiatry 22:215-226.

Watson CJ, Baghdoyan HA, and Lydic R (2010) Neuropharmacology of sleep and wakefulness. Sleep Med Clin 5:513-528.

Wiley JL, Compton DR, Dai D, Lainton JA, Phillips M, Huffman JW, and Martin BR (1998) Structure-activity relationships of indole- and pyrrole-derived cannabinoids. $J$ Pharmacol Exp Ther 285:995-1004.

Wilson SJ, Lovenberg TW, and Barbier AJ (2003) A high-throughput-compatible assay for determining the activity of fatty acid amide hydrolase. Anal Biochem 318 : $270-275$.

Woodhams SG, Chapman V, Finn DP, Hohmann AG, and Neugebauer V (2017) The cannabinoid system and pain. Neuropharmacology 124:105-120.

Xu J, Antion MD, Nomura T, Kraniotis S, Zhu Y, and Contractor A (2014) Hippocampal metaplasticity is required for the formation of temporal associative memories. J Neurosci 34:16762-16773.

Yi B, Nichiporuk I, Nicolas M, Schneider S, Feuerecker M, Vassilieva G, Thieme D, Schelling G, and Choukèr A (2016) Reductions in circulating endocannabinoid 2 arachidonoylglycerol levels in healthy human subjects exposed to chronic stressors. Prog Neuropsychopharmacol Biol Psychiatry 67:92-97.

Zou S and Kumar U (2018) Cannabinoid receptors and the endocannabinoid system: signaling and function in the central nervous system. Int J Mol Sci 19:833.

Address correspondence to: Ryan M. Wyatt, Janssen Research and Development, LLC, 3210 Merryfield Row, San Diego, CA 92121. E-mail: rwyatt2@its.jnj.com 